\title{
Part 8: Education, Implementation, and Teams 2015 International Consensus on Cardiopulmonary Resuscitation and Emergency Cardiovascular Care Science With Treatment Recommendations
}

\author{
Farhan Bhanji, Co-Chair*; Judith C. Finn, Co-Chair*; Andrew Lockey; Koenraad Monsieurs; Robert \\ Frengley; Taku Iwami; Eddy Lang; Matthew Huei-Ming Ma; Mary E. Mancini; Mary Ann McNeil; \\ Robert Greif; John E. Billi; Vinay M. Nadkarni; Blair Bigham; on behalf of the Education, \\ Implementation, and Teams Chapter Collaborators
}

\section{Introduction}

Current evidence demonstrates considerable variability in cardiac arrest survival in and out of hospital and, therefore, substantial opportunity to save many more lives. ${ }^{1-3}$ The Formula for Survival ${ }^{4}$ postulates that optimal survival from cardiac arrest requires high-quality science, education of lay providers and healthcare professionals, and a well-functioning Chain of Survival ${ }^{5}$ (implementation).

The Education, Implementation, and Teams (EIT) Task Force of the International Liaison Committee on Resuscitation (ILCOR) set out to define the key PICO (population, intervention, comparator, outcome) questions related to resuscitation education (including teamwork skills) and systems-level implementation that would be reviewed by 2015 . The selection of questions was supported through the use of an online anonymous task force member-only voting process where the results were considered in the ultimate consensus decisions of the task force. Topics from the 2010 evidence review process were scrutinized for relevance, the potential to improve outcomes, and the likelihood of new evidence being published since 2010. Finally, PICO questions for which the Grading of Recommendations, Assessment, Development, and Evaluation (GRADE) process was not as well developed at the time of PICO selection were deferred until at least after the 2015 cycle. We planned to reduce the total number of PICO questions reviewed to provide more in-depth and evidence-based reviews of the included questions. New topics were determined on the basis of the evolving literature and changes in resuscitation practice. Input on the selection of PICO questions was sought from the general public through the ILCOR website and from ILCOR member resuscitation councils through their council chairs and individual task force members.

\section{The GRADE Process}

The EIT Task Force performed detailed systematic reviews based on the recommendations of the Institute of Medicine of the National Academies ${ }^{6}$ and using the methodological approach proposed by the GRADE Working Group.? After identification and prioritization of the questions to be addressed (using the PICO format), ${ }^{8}$ with the assistance of information specialists, a detailed search for relevant articles was performed in each of 3 online databases (PubMed, Embase, and the Cochrane Library).

By using detailed inclusion and exclusion criteria, articles were screened for further evaluation. The reviewers for each question created a reconciled risk of bias assessment for each of the included studies, using state-of-the-art tools: Cochrane for randomized controlled trials (RCTs), ${ }^{9}$ Quality Assessment of Diagnostic Accuracy Studies (QUADAS)-2 for studies of diagnostic accuracy, ${ }^{10}$ and GRADE for observational studies that inform both therapy and prognosis questions. ${ }^{11}$

GRADE Evidence Profile tables ${ }^{12}$ were then created to facilitate an evaluation of the evidence in support of each of the critical and important outcomes. The quality of the evidence (or confidence in the estimate of the effect) was categorized as high, moderate, low, or very low, ${ }^{13}$ based on the study methodologies and the 5 core GRADE domains of risk of bias, inconsistency, indirectness, imprecision, and other considerations (including publication bias)..$^{14}$

These evidence profile tables were then used to create a written summary of evidence for each outcome (the Consensus on Science statements). Whenever possible, consensus-based treatment recommendations were then created. These recommendations (designated as strong or weak) were accompanied by an overall assessment of the evidence and a statement from the task force about the values and preferences that underlie the recommendations.

The American Heart Association requests that this document be cited as follows: Bhanji F, Finn JC, Lockey A, Monsieurs K, Frengley R, Iwami T, Lang E, Ma MH, Mancini ME, McNeil MA, Greif R, Billi JE, Nadkarni VM, Bigham B; on behalf of the Education, Implementation, and Teams Chapter Collaborators. Part 8: education, implementation, and teams: 2015 International Consensus on Cardiopulmonary Resuscitation and Emergency Cardiovascular Care Science With Treatment Recommendations. Circulation. 2015;132(suppl 1):S242-S268.

*Co-chairs and equal first co-authors.

This article has been co-published in Resuscitation. Published by Elsevier Ireland Ltd. All rights reserved.

(Circulation. 2015;132[suppl 1]:S242-S268. DOI: 10.1161/CIR.0000000000000277.)

(C) 2015 American Heart Association, Inc., European Resuscitation Council, and International Liaison Committee on Resuscitation. 
Further details of the methodology that underpinned the evidence evaluation process are found in "Part 2: Evidence Evaluation and Management of Conflicts of Interest."

To our knowledge, this is the first time that GRADE has been applied on a large scale to education literature in health. Detailed review of the evidence, the Consensus on Science statements, and treatment recommendations occurred within the task force, and most final recommendations reflect the consensus of the task force. In some instances, the task force could not reach consensus and a vote was required; greater than $50 \%$ agreement was adequate for standard decisions on wording, and $70 \%$ agreement was required for treatment recommendations that were discordant with the quality of evidence.

The EIT Task Force spent considerable time deliberating on the scoring of the importance of outcomes according to the GRADE approach, particularly with respect to educational studies. In contrast to clinical studies, where direct patient outcomes are commonly measured, in educational research, which often include manikin studies, participant learning outcomes are very common. After considerable task force discussion, for education PICO questions, patient-related outcomes and actual performance in the clinical setting were deemed the critical outcomes, with learning-related outcomes (immediate and longer retention) classed as important. Kirkpatrick's classic model of Program Evaluation ${ }^{15}$ as well as McGaghie's ${ }^{16}$ T1 to T3 for simulation research both align with the notion that patient-related (and system-related) outcomes are more relevant than transfer of learning from the education programs to the clinical environment, which in turn is more important than isolated demonstration of learning in a training setting. Recognizing the considerable body of evidence demonstrating a decay of resuscitation skills within weeks to months after a course, long-term retention of learning was considered a more robust outcome than learning assessed at the time of the training. Similarly, resuscitation is considered a (psychomotor or leadership/teamwork) skill; therefore, "skills" were considered to be higher-level outcomes than "knowledge." The published resuscitation education literature and subsequent GRADE analysis were frequently limited by the heterogeneous nature of the interventions (with frequent downgrades for inconsistency) and the quality of the assessment tools (outcome measures). In keeping with systematic review methodology, meta-analysis was conducted in specific PICO questions only when studies of similar design, interventions, and target populations reported comparable outcomes.

The EIT Task Force reviewed 17 PICO questions, which was a reduction of 15 questions from 2010. The questions selected included the following:

Basic Life Support Training

- Cardiopulmonary resuscitation (CPR) instruction methods (self-instruction versus traditional) (EIT 647)

- Automated external defibrillator (AED) training methods (EIT 651)

- Timing for basic life support (BLS) retraining (EIT 628)

- Resource-limited settings (EIT 634)

- BLS training for high-risk populations (EIT 649)

- Compression-only CPR training (EIT 881)
Advanced Life Support Training

- Precourse preparation for advanced life support (ALS) courses (EIT 637)

- High-fidelity manikins in training (EIT 623)

- Team and leadership training (EIT 631)

- Timing for advanced resuscitation training (EIT 633)

Implementation

- Implementation of guidelines in communities (EIT 641)

- Cardiac arrest centers (EIT 624)

- Social media technologies (EIT 878)

- Measuring performance of resuscitation systems (EIT 640)

- CPR feedback devices in training (EIT 648)

- Debriefing of resuscitation performance (EIT 645)

- Medical emergency teams (METs) for adults (EIT 638)

\section{Summary of New Treatment Recommendations}

The following is a summary of the most important new reviews or changes in recommendations for education, implementation, and teams since the last ILCOR review, in 2010:

Training

- High-fidelity manikins may be preferred to standard manikins at training centers/organizations that have the infrastructure, trained personnel, and resources to maintain the program.

- CPR feedback devices (providing directive feedback) are useful for learning psychomotor CPR skills.

- One- to 2-year retraining cycles are not adequate to maintain competence in resuscitation skills. The optimal retraining intervals are yet to be defined, but more frequent training may be helpful for providers likely to encounter a cardiac arrest.

Systems Level

- You can't improve what you can't measure, so systems that facilitate performance measurement and quality improvement initiatives are to be used where possible.

- Data-driven performance-focused debriefing can help improve future performance of resuscitation teams.

- Out-of-hospital cardiac arrest (OHCA) victims should be considered for transport to a specialist cardiac arrest center as part of a wider regional system of care.

- There have been advances in the use of technology and social media for notification of the occurrence of suspected OHCA and sourcing of bystanders willing to provide $\mathrm{CPR}$.

\section{BLS Training}

BLS is foundational in the care of cardiac arrest victims. For the OHCA victim, the goal is to increase rates of bystander CPR and deliver prompt defibrillation, because these are the major determinants of the community Chain of Survival. Unfortunately, only a minority of cardiac arrest victims actually receive bystander CPR, and it is difficult for potential rescuers to overcome barriers such as panic, fear of harming the victim, concern about the rescuers' inability to perform CPR 
correctly, physical limitations, fear of liability or infection, or in some instances the victim's characteristics. ${ }^{17}$ Recent training in CPR, ${ }^{17-19}$ along with dispatcher-assisted CPR, ${ }^{20,21}$ may help overcome these barriers and save more lives. For healthcare professionals, it is the quality of CPR delivered that is critical, because poor compliance with recommended guidelines has been associated with lower survival. ${ }^{22,23}$ Suboptimal CPR is common ${ }^{24}$ but should be considered a preventable harm, and quality improvement processes should be implemented to try to minimize its occurrence.

The ILCOR EIT Task Force chose the following PICO questions as part of the review of BLS training:

- Video- or computer-assisted self-instruction versus traditional courses

- Alternate methods to train in AED use

- Timing of BLS retraining

An additional PICO question on the use of CPR feedback devices in training was also conducted and is documented later in this article, along with the corresponding PICO questions on the use of feedback devices in clinical practice (BLS 361) and the use of feedback devices as part of the quality improvement process (EIT 640).

\section{CPR Instruction Methods (Self-Instruction Versus Traditional) (EIT 647)}

Among students who are taking BLS courses in an educational setting $(\mathrm{P})$, does video or computer self-instructions (I), compared with traditional instructor-led courses (C), change survival, skill performance in actual resuscitations, skill performance at 1 year, skill performance at course conclusion, cognitive knowledge $(\mathrm{O})$ ?

\section{Consensus on Science}

No studies addressed the critical outcomes of skill performance in actual resuscitations or survival of patients.

For the important outcome of cognitive knowledge, we have identified low-quality evidence (downgraded for serious risk of bias and imprecision) from 4 RCTs with a total of 370 students showing no differences between self-instruction and instructor-led courses (using a multiple-choice questionnaire at course conclusion and at 2 months to 1 year). ${ }^{25-28}$

For the important outcome of skill performance at course conclusion, we have identified very-low-quality evidence (downgraded for risk of bias, inconsistency, and imprecision) from 9 RCTs ${ }^{25,29-36}$ and 1 randomized cluster-controlled trial ${ }^{37}$ with a total of 2023 students showing no differences between self-instruction and instructor-led courses based on failure to pass total performance evaluation by instructors using checklists (relative risk [RR], 1.09; 95\% confidence interval [CI], 0.66-1.83).

For the important outcome of skill performance at $\mathbf{1}$ year, we have identified low-quality evidence (downgraded for risk of bias and imprecision) from 2 RCTs with a total of 234 students showing no differences between self-instruction and traditional instruction based on failure to pass the total performance evaluation by instructors using checklists (RR, $0.91 ; 95 \%$ CI, 0.61-1.35). ${ }^{28,38}$

\section{Treatment Recommendations}

We suggest that video and/or computer-based self-instruction with synchronous or asynchronous hands-on practice may be an effective alternative to instructor-led courses (weak recommendation, very-low-quality evidence).

\section{Values, Preferences, and Task Force Insights}

Despite heterogeneity in the delivery of video and/or computer-based instruction and in the evaluation methods among different studies, we make this recommendation based on the absence of differences in the outcomes between self-instruction versus instructor-led courses. In making this recommendation, we place higher value on the potential reduction in time and resources with self-instruction, which could translate to increased CPR training.

The EIT Task Force recognized the considerable heterogeneity in the interventions on self-instruction (computer versus video assisted; with or without hands-on practice) and challenge with lumping them together (ie, a poorly designed computer-based learning activity is very different from a welldesigned one), yet they are grouped together in the GRADE process. Nonetheless, the task force developed consensus that this was an important PICO question that had the potential to increase the number of lay providers available to respond to cardiac arrests and potentially the subsequent survival for victims in a time- and resource-wise manner.

\section{Knowledge Gaps}

- Do students receiving self-instruction courses have better skill performance in actual resuscitations and further improve the rate of return of spontaneous circulation (ROSC) and survival to hospital discharge of patients when compared with those receiving traditional courses?

- The teaching material of the video or the computer and different type of self-instruction teaching courses might affect the learning effect.

\section{AED Training Methods (EIT 651)}

Among students who are taking AED courses in an educational setting $(\mathrm{P})$, does any specific training intervention (I), compared with traditional lecture/practice sessions (C), change clinical outcome, skill performance in actual resuscitations, skill performance at 1 year, skill performance at course conclusion, cognitive knowledge, use of AEDs $(\mathrm{O})$ ?

\section{Consensus on Science}

No study addressed the critical outcomes of skill performance in an actual resuscitation or patient outcome.

All studies for this PICO question were manikin based, and all participants were adults. ${ }^{16,36,37,39-42}$ The included studies used manikin-based scenarios as the standard method for assessment, and end points did not extend beyond skill retention after 6 months. Substantial heterogeneity was found for interventions and controls, and for time points of assessment. Except for 2 studies $^{40,41}$ none investigated AED training in isolation. All other studies address the whole sequence of BLS together with AED related outcomes.

To account for the nature of training, 4 subquestions were specified. For both groups of lay providers and 
healthcare providers, the question was subdivided into (a) self-instruction without (or with minimal) instructor involvement versus a traditional instructor-led course, and (b) self-instruction combined with instructor-led versus a traditional course.

\section{For Lay Providers}

For the subquestion of self-instruction without (or with minimal) instructor involvement versus a traditional instructor-led course, we identified low-quality evidence (downgraded for indirectness) addressing the important outcome of skill retention after 2 to 6 months. ${ }^{16,36,40,41}$

For 2 of the investigated DVD-based teaching methods, the RR to pass the overall test directly after the course was only 0.36 (95\% CI, 0.25-0.53), and 0.35 (95\% CI, 0.24-0.51) if compared with instructor-led training. ${ }^{40}$ No significant difference was found 2 months after training when comparing a computer-learning-only course to instructor-led training. ${ }^{16}$ No significant difference was reported for AED performance (time to first shock and AED placement) for a video self-learning intervention of 30 minutes in comparison with instructor-led training of 3 to 4 hours. ${ }^{36}$ Training for senior citizens (video self-training of 11 minutes plus 45 minutes of manikin training plus minimal instructor) was not significantly different compared with the control group. This study also suggests a saving of resources by the alternative training method. ${ }^{41}$

For the subquestion of self-instruction combined with instructor-led versus traditional courses, we identified lowquality evidence (downgraded for indirectness) addressing the important outcomes of skill retention after $\mathbf{2}$ months for the following 2 studies:

- Interactive computer session of 45 minutes plus 45 minutes of instructor-based practice led to results comparable with those from a traditional course of the same duration. ${ }^{16}$ AED skills remained rather stable over 2 months, while CPR skills deteriorated significantly.

- A 9-minute DVD plus manikin training plus scenario training was inferior to traditional training, with an RR to pass the overall test of 0.55 , which increased to 0.84 after 2 months. ${ }^{40}$ This may indicate a potential learning effect of the short postcourse test.

\section{For Healthcare Providers}

For the subquestion of self-instruction without (or with minimal) instructor involvement versus traditional instructorled courses, we identified very-low-quality evidence (downgraded for indirectness and imprecision) addressing the important outcome of skill performance at end of course, or 2 weeks after completion.

Isolated self-instructed training was as efficient as traditional training, but testing was limited to the end of the course. ${ }^{37}$ No differences were found between groups, but significant time (and financial) savings were reported. ${ }^{39}$ However, the sample size was very small. Another study showed worse results for theory-only training, but this study was flawed because the control group was inadequate. ${ }^{42}$

For the subquestion of self-instruction combined with instructor-led versus traditional courses, we identified low-quality evidence (downgraded for indirectness) for the important outcomes of skill performance at end of course, or 2 weeks after completion. Training time was reduced while performance was only slightly reduced. A 40-minute skills lab training plus instructor was associated with a higher rate of mistakes in AED operations. ${ }^{37}$ In another study, no differences were found between groups, but significant time (and financial) savings were reported in the self-instruction combined with instructor-training group ${ }^{39}$; however, the sample size was very small.

\section{Treatment Recommendation}

For lay providers learning AED skills, we suggest that selfinstruction combined with short instructor-led training may replace longer traditional courses (weak recommendation, low-quality evidence).

For healthcare providers learning AED skills, we suggest that self-directed training (as short as 40 minutes) may be used in place of traditional training (weak recommendation, lowquality evidence).

\section{Values, Preferences, and Task Force Insights}

In making this recommendation, we place value on pragmatic considerations such that if instructor-led training is not available, then self-directed training (or no training at all ["just do it"]) is an acceptable pragmatic option to use AED as stated in the 2010 International Consensus on Cardiopulmonary Resuscitation and Emergency Cardiovascular Care Science With Treatment Recommendations (CoSTR). ${ }^{18,19}$

Very little research was conducted on AED teaching outside of the context of a (standard) BLS course (only 2 studies $^{40,41}$ reported on that setting). All data were extracted from studies in the context of BLS teaching.

The ILCOR 2010 CoSTR stated that laypeople and healthcare providers could use an AED without training ${ }^{16,43,44}$ and that untrained individuals could deliver a shock with an AED. ${ }^{45-47}$ The current systematic review investigated whether a specific training intervention in an educational setting changed clinical or learning outcomes.

The original intent was to produce a single consensus on science with treatment recommendations based on a single PICO question. As the literature was reviewed, it became clear that there was marked heterogeneity in populations studied and the types of interventions, so multiple subsections were developed with multiple treatment recommendations.

\section{Knowledge Gaps}

- Properly powered studies are needed where the primary outcome is AED use in the clinical setting and patient outcomes are considered.

- The optimal duration of AED training is still unclear.

- The effectiveness and optimal timing of brief refresher training should be evaluated.

- The most suitable methods to train children/adolescents need to be determined. 


\section{Timing for BLS Retraining (EIT 628)}

Among students who are taking BLS courses (P), does any specific interval for update or retraining (I), compared with standard practice (ie, 12 or 24 monthly) (C), change patient outcomes, skill performance in actual resuscitations, skill performance at 1 year, skill performance at course conclusion, cognitive knowledge $(\mathrm{O})$ ?

\section{Consensus on Science}

For critical outcomes of patient outcome and skill performance during actual resuscitation, we found no published evidence.

For the important outcome of skill performance 3 to 12 months after initial training, we identified very-low-quality evidence (downgraded for risk of bias, inconsistency, and indirectness) from $3 \mathrm{RCTs}^{48-50}$ and 2 non-RCTs ${ }^{51,52}$ evaluating the effects of additional updates or retraining compared with standard practice (12-24 monthly). The heterogeneous nature of the studies prevented pooling of data. Two studies (1 RCT and 1 non-RCT) evaluated the effect of high-frequency, lowdose training (6 minutes monthly practice and every-2-weeks video reminder) after standard BLS courses and demonstrated benefit on CPR performance (compression depth, $40.3 \pm 6.6$ versus $36.5 \pm 7.7 \mathrm{~mm}$ ) ${ }^{50}$ and on time to shock delivery (time $[$ mean \pm SD], $60.0 \pm 12.9$ versus $73.6 \pm 22 \mathrm{~s}) .^{52}$ Two other RCTs and 1 non-RCT conducting a variety of retraining and evaluating 5 to 6 months after the retraining showed no benefit on chest compression quality or time to shock delivery. $48,49,51$

For the important outcome of cognitive knowledge, we identified very-low-quality evidence (downgraded for risk of bias, inconsistency, and indirectness) from $1 \mathrm{RCT}^{48}$ demonstrating improved self-reported confidence score ( 96 versus 92; $P=0.038$ ) after additional traditional BLS retraining and 1 non-RCT ${ }^{52}$ demonstrating increased willingness to perform CPR (RR, 0.62; 95\% CI, 0.40-0.96) after high-frequency, low-dose training (every-2-weeks video reminder). ${ }^{52}$

Studies evaluating BLS skill retention demonstrated rapid decay in BLS skills (eg, chest compression quality and time to defibrillation) within 3 to 12 months after initial training. ${ }^{18,19}$

\section{Treatment Recommendations}

There is insufficient evidence to recommend the optimum interval or method for BLS retraining for laypeople.

Because there is evidence of skills decay within 3 to 12 months after BLS training and evidence that frequent training improves CPR skills, responder confidence, and willingness to perform CPR, we suggest that individuals likely to encounter cardiac arrest consider more frequent retraining (weak recommendation, very-low-quality evidence).

\section{Values, Preferences, and Task Force Insights}

In making this recommendation, we place emphasis on the need for individuals and organizations to determine the importance of BLS skill maintenance, based on their local context and the feasibility of more frequent training.

The search strategy for this PICO question focused on lay providers, but the results were considered to be generalizable. The EIT Task Force debated at length whether to recommend a specific interval for retraining, but opted to leave this to the discretion of the organizations involved because the only evidence is that CPR skills decay before the currently recommended 12- to 24-month retraining intervals.

\section{Knowledge Gaps}

- There is limited evidence evaluating the effect of shorter intervals between BLS courses.

- High-frequency, low-dose training shows some promise, and could potentially enhance BLS training and reduce skill decay. More studies are needed to confirm the role of such training.

- There is significant heterogeneity of initial training, timing and contents of retraining, and outcomes among current studies. There is a need for development of guidelines to ensure uniform testing and reporting in BLS training and simulation research.

\section{Basic Life Support: Other Considerations}

There are several issues that impact the optimal design and implementation of BLS training within communities. The ILCOR EIT Task Force chose to focus on PICO questions that aligned with the GRADE methodology for intervention questions and that could have a relatively immediate impact to help save more lives or could identify important knowledge gaps that require further research.

For 2015, the ILCOR EIT Task Force chose to focus on

- Educational approaches to resuscitation training in resource-limited settings

- Focused training of likely rescuers for high-risk populations

- The impact of training communities to use compressiononly CPR

\section{Resource-Limited Settings (EIT 634)}

Among students who are taking BLS or ALS courses in a resource-limited educational setting $(\mathrm{P})$, does any educational approach (I), compared with other approaches (C), change clinical outcome, skill performance in actual resuscitations, skill performance at 1 year, skill performance at time between course conclusion and 1 year, skill performance at course conclusion, cognitive knowledge $(\mathrm{O})$ ?

\section{Consensus on Science}

For the critical outcomes of change in clinical outcome and skill performance in actual resuscitations and the important outcome of skill performance at 1 year, we found no evidence in low-resource settings.

For the important outcome of skill performance at time of course conclusion and 1 year, we found very-low-quality evidence (downgraded for serious risk of bias, imprecision, and possible publication bias) from 2 RCTs..$^{53,54}$ One study tested cognitive and skill retention 3 weeks after ALS refresher training in 3 arms, namely simulation (traditional course format) versus multimedia (computer-based learning) and selfdirected reading. ${ }^{53}$ In another study, students were tested at 3 and 6 months after training. ${ }^{54}$ This study involved BLS training in a traditional course format versus limited instruction (larger student-to-instructor ratio) and self-directed computer-based 
learning. All modalities were shown to be equivocal or to have mixed but not constant benefit over traditional format.

For the important outcome of skill performance at course conclusion, we identified $6 \mathrm{RCTs}^{53-58}$ and 1 observational study. ${ }^{59}$ Studies varied significantly in the subject taught from BLS to ALS, range of participants (paramedic students, medical students in various stages of training, nursing staff, general healthcare providers), duration of course, and training methods. Educational strategies included traditional course format versus computer-based learning, telemedicine, self-directed reading, limited instruction (larger student-toinstructor ratio), 4-stage skill teaching, video instruction, and video-based group feedback. Studies ranged from very-lowquality evidence ${ }^{53}$ (downgraded for serious risk of bias and imprecision) to moderate-quality evidence ${ }^{55-58}$ (downgraded for imprecision).

Because the outcome of skill performance in all 7 studies $^{53-59}$ demonstrated equivocal or minimal benefit in skill performance compared with traditional course format, we suggest the possibility of using other training methods for teaching BLS or ALS. However, the heterogeneity of the studies makes it unclear what this alternative method might be (weak recommendation, low-quality evidence).

For the important outcome of cognitive knowledge, we identified 4 RCTs: 2 were of very low quality (downgraded for serious risk of bias, imprecision, and possible publication bias), ${ }^{53,54} 1$ was of low quality (downgraded for risk of bias and imprecision), ${ }^{57}$ and 1 was of moderate quality (downgraded for imprecision). ${ }^{55}$ These studies differed in the teaching methods used to compare cognitive outcome, including simulation (traditional course format), multimedia (computer-based learning), self-directed reading, limited instruction (larger student-to-instructor ratio), and self-directed computer-based learning. In comparing traditional course format to alternative teaching strategies for BLS or ALS training, there were some studies showing slight cognitive knowledge benefit of various teaching strategies, but no constant benefit over the traditional method, and no studies could be pooled together to strengthen a recommendation or quality of evidence.

All of the RCTs included few participants. Therefore, we suggest the possibility of using alternative educational strategies (weak recommendation, low-quality evidence).

\section{Treatment Recommendations}

We suggest that alternative instructional strategies would be reasonable for BLS or ALS teaching in low-income countries (weak recommendation, very-low-quality evidence). The optimal strategy has yet to be determined.

\section{Values, Preferences, and Task Force Insights}

In making this recommendation, we consider that cost of and access to training may play a large role in the ability of healthcare workers to receive training in BLS and ALS in lowincome countries.

Some of the alternative techniques for BLS or ALS teaching identified in this review may be less expensive and require less instructor resource than a traditional teaching format, and may enable wider dissemination of BLS and ALS training in low-income countries.
The heterogeneity of the content taught (eg, BLS versus ALS), the learner populations, and the different instructional methods studied in resource-limited settings were challenging to summarize as a single systematic review. As the body of evidence develops, this PICO question may benefit from subdivision across content taught, learner populations, and instructional methods.

\section{Knowledge Gaps}

- Educational resources vary from one country to another. From the studied data in low-resource settings, there is no one-size-fits-all approach, and therefore, specific educational strategies need to be developed and tested for specific low-resource countries and settings.

\section{Basic Life Support Training for High-Risk Populations (EIT 649)}

For people at high risk of OHCA (P), does focused training of likely rescuers (eg, family or caregivers) (I) compared with no such targeting (C), change survival with favorable neurologic outcome at discharge, ROSC, bystander CPR performance, number of people trained in CPR, willingness to provide CPR $(\mathrm{O})$ ?

\section{Consensus on Science}

We found 32 studies relating to CPR training in likely rescuers (eg, family or caregivers) of high-risk OHCA groups. These studies used varying methods for CPR training and assessment of outcomes.

In brief, there is insufficient evidence on patient outcomes to support or refute the use of training interventions in highrisk groups. ${ }^{60-70}$ Existing evidence on educational outcomes suggest likely rescuers are willing to be trained, ${ }^{63,71-77}$ are likely to share training with others, ${ }^{71,74,75,78-80}$ are unlikely to seek training on their own, ${ }^{63,79}$ and, after training, are compe-

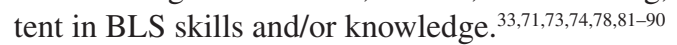

For the critical outcomes of survival with favorable neurologic outcome at discharge and $\mathrm{ROSC}$, we have identified low-quality evidence (downgraded for risk of bias, indirectness, and imprecision) from $3 \mathrm{RCTs}^{60,61,64}$ and very-low-quality evidence (downgraded for risk of bias) from 8 non-RCTs. ${ }^{63,65-70,91}$ The heterogeneous nature of the studies prevents pooling of data. In individual studies, there were insufficient numbers of events, with significant loss to follow-up, to be confident in the direction of the survival estimates, particularly for adult cardiac patients.

The 3 RCTs followed high-risk patients for subsequent OHCA events and survival as secondary outcomes, so were not adequately powered for these outcomes..$^{60,61,64}$ One study reported 4 out-of-hospital deaths in 65 adult cardiac patients at 6 months $(2 / 24$ in the control group and 2/41 in the CPRtrained group). ${ }^{61} \mathrm{~A}$ larger study, which was subject to high loss to follow-up, documented 13 OHCA events among high-risk children within 12 months after training of parents and other caretakers; all of these children were successfully resuscitated, and all were in the trained groups, with no events reported in the control group. ${ }^{64}$ The third RCT reported 71 OHCA events in the home among 7001 adult high-risk patients with training (CPR or CPR with AED); survival was $12 \%$, with an indirect 
comparison made to $2 \%$ survival for OHCA events in the home from the literature. ${ }^{60}$

Eight non-RCTs were of very-low-quality evidence. ${ }^{63,65-70,91}$ The majority of these studies relied on selfreported outcomes and were subject to high loss to follow-up or small sample sizes. One study documented higher survival rates for OHCA events in centers offering CPR training for high-risk children $(28 / 41,46 \%)$ when compared with centers offering no training $(0 / 24,0 \%)$; however, it is not reported whether the parents of OHCA children in either group had any CPR training, including the CPR training offered. ${ }^{66}$ Two studies trained the parents of high-risk infants. ${ }^{33,69}$ The first study reported $75 \%$ survival for 8 OHCA events, ${ }^{24}$ all with good or stable neurologic status, and the second study reported $100 \%$ for $7 \mathrm{OHCA}$ events. ${ }^{59}$ Among adult cardiac patients, who were followed-up for varying durations after training, there were very few OHCA events: 1 very small study $(n=33)$ reported no events or deaths ${ }^{70} ; 3$ studies report single OHCA events during follow-up after training, all of whom died ${ }^{63,67,68}$; and 1 study reported $14 \mathrm{OHCA}$ events and 12 deaths among $97 \mathrm{OHCA}$ survivors after training (CPR or CPR with AED). ${ }^{65}$

For the important outcome of bystander CPR performance-subsequent utilization of skills, we identified lowquality evidence (downgraded for risk of bias and imprecision) from 2 RCTs $^{61,64}$ and very-low-quality evidence (downgraded for risk of bias) from 7 non-RCTs. ${ }^{63,66-70,91}$ The heterogeneous nature of the studies prevents pooling of data. In individual studies, there were too few events, with significant loss to follow-up, to be confident in the direction of the estimates, particularly for adult cardiac patients.

The 2 RCTs followed patients for OHCA events and bystander CPR. ${ }^{61,64}$ One study found bystander CPR was not performed in any of the 4 adult OHCA cardiac-related deaths ( 2 in control, 2 in intervention). ${ }^{61}$ The other study reported 13 OHCA events in high-risk infants, all of whom received CPR by trained parents, with no OHCAs occurring in the control group. ${ }^{64}$

Seven non-RCTs followed patients for OHCA events and determined whether bystander CPR was performed. ${ }^{63,66-70,91}$ One study documented higher bystander CPR rates for OHCA events in centers offering CPR training to parents of high-risk children $(28 / 41,68 \%)$ compared with centers providing no training $(0 / 24,0 \%)$, but it is not reported whether the parents in either group were CPR trained. ${ }^{66}$ Two studies documented bystander CPR rates of $100 \%$ for 13 OHCA events in highrisk infants (bystander CPR status for 1 additional event was unknown). ${ }^{69,91}$ In 2 small studies of adult cardiac patients, there were single OHCA events, and trained individuals were either not present at the time ${ }^{67}$ or physically unable to perform CPR. ${ }^{68}$ A larger study describes CPR-trained family members using CPR on 4 occasions; 3 were successful. ${ }^{63}$

For the important outcome of CPR skills performance and retention, we identified moderate-quality evidence (downgraded for risk of bias) from $3 \mathrm{RCTs}^{33,71,81}$ and verylow-quality evidence (downgraded for risk of bias) from 12 non-RCTs. ${ }^{73,74,78,82-90}$ Although these studies used different methods for CPR training and assessment, they consistently report competent CPR performance and/or knowledge immediately after training, ${ }^{33,73,78,81-90}$ which is usually retained in the short term ${ }^{71,73,85,88}$ but declines over longer periods of followup without retraining or reminders. ${ }^{84}$

For the important outcome of number of people trained, we identified low-quality evidence (downgraded for risk of bias and indirectness) from $2 \mathrm{RCTs}^{71,79}$ and verylow-quality evidence (downgraded for risk of bias) from 4 non-RCTs. ${ }^{74,75,78,80}$ The heterogeneous nature of the studies prevents pooling of data, but overall the data suggest that family members and caregivers are unlikely to seek training on their own ${ }^{63,79}$ but, when trained, are likely to share the training with others. ${ }^{71,74,75,78}$

The 2 RCTs examined the question from different perspectives. ${ }^{71,79}$ The first study reported CPR kit sharing rates by trained family members of cardiac patients, with a mean of 2.0 ( $\mathrm{SD} \pm 3.4$ ) additional family members in the continuous chest compression CPR group versus a mean of $1.2(\mathrm{SD} \pm 2.2)$ in the conventional CPR group $(P=0.03) .{ }^{71}$ In the second study, adult cardiac patients were more likely to follow prescribed advice by a physician to purchase a CPR training kit than to take a traditional CPR class $(P=0.0004)$, although few followed any advice (12/77 purchased a CPR training kit, and 0/79 underwent CPR training through a traditional CPR class). ${ }^{79}$

Five non-RCTs also used different methods to examine the question..$^{63,74,75,78,80}$ One study targeted 190 OHCA survivors, with 50 of 101 responding, and 20 patients and 71 family members and friends were subsequently trained. ${ }^{80}$ In 1 study, free mass CPR training sessions were provided, and an increase in those attending training because of heart disease after a targeted recruitment campaign (5.6\% to $13.2 \%)$ was documented. In 1 study, ${ }^{78} 49 \%$ shared a CPR DVD with family and/or friends, and in another, ${ }^{75} 79 \%$ shared the kit with at least 2 family members/friends. One study documented that only $18 \%$ of untrained family members sought training on their own in the follow-up period of $21 \pm 6$ months. ${ }^{63}$

For the important outcome of willingness to provide CPR, we identified moderate-quality evidence (downgraded for risk of bias) from $2 \mathrm{RCTs}^{71,76}$ and very-low-quality evidence (downgraded for risk of bias) from 6 non-RCTs. ${ }^{63,72-75,77}$ The heterogeneous nature of the studies prevents pooling of data, but there was a strong signal toward willingness to provide $\mathrm{CPR}$ if required in all studies.

Two RCTs ${ }^{71,76}$ were identified as moderate quality of evidence. The first RCT documented that trainees in the continuous chest compression CPR group were more likely to rate themselves as very comfortable with the idea of using CPR skills in actual events than were the conventional CPR trainees (34\% versus $28 \%$; $P=0.08) .{ }^{71}$ The second $\mathrm{RCT}$ found that the majority "would absolutely" be willing to perform CPR if required. $^{76}$

Very-low-quality evidence was identified from 6 nonRCTs. ${ }^{63,72-75,77}$ In 3 of the studies, ${ }^{63,72,74}$ the vast majority of trained individuals stated they would use CPR if needed (79\%-99\%), and 1 study reported that all subjects felt neutral to somewhat confident in their comfort with providing CPR. ${ }^{75}$ One study reported that $98 \%$ of those trained stated that they "agreed" or that they "maybe" would perform first aid (including CPR) correctly at 1-year follow-up. ${ }^{72}$ Another study found a slight decrease in comfort level with CPR use within 6 months after training. ${ }^{75}$ 


\section{Treatment Recommendations}

We recommend the use of BLS training interventions that focus on high-risk populations, based on the willingness to be trained and the fact that there is low harm and high potential benefit (strong recommendation, low-quality evidence).

\section{Values, Preferences, and Task Force Insights}

In making this recommendation, we place higher value on the potential benefits of patients receiving CPR by a family member or caregiver, and the willingness of this group to be trained and to use skills if required. We place lesser value on associated costs and the potential that skills may not be retained without ongoing CPR training. Because cardiac arrest is life threatening, the likelihood of benefit is high relative to possible harm.

\section{Knowledge Gaps}

There is a need for

- Higher-quality research

- Adequately powered studies reporting critical clinical outcomes

- Studies examining the cost-effectiveness of CPR training for family members of high-risk patients

- Studies examining innovative CPR training versus conventional CPR training (versus no training)

- Studies with standardized/objective methods of assessment for CPR performance (real-time data recording)

\section{Compression-Only CPR Training (EIT 881)}

Among communities that are caring for patients in cardiac arrest in any setting (P), does teaching compression-only CPR (I), compared with conventional CPR (C), change survival rates, bystander CPR rates, willingness to provide CPR $(\mathrm{O})$ ?

\section{Consensus on Science}

For the critical outcome of neurologically intact survival at hospital discharge, we found very-low-quality evidence (downgraded for serious imprecision) from 2 observational studies $(n=1767)^{92,93}$ that documented survival to hospital discharge for adults receiving bystander CPR from the same statewide database; one reported on events of cardiac origin, ${ }^{92}$ and the other reported on events of noncardiac origin. ${ }^{93}$ Both studies demonstrated no difference in neurologically intact survival (odds ratio [OR], 1.41; 95\% CI, 0.92-2.14).

For the critical outcome of bystander CPR rates, we found very-low-quality evidence (downgraded for serious imprecision and serious risk of bias) from 1 observational study, which showed a higher proportion of bystander CPR performed with compression-only CPR than with conventional CPR over the 5-year study period (34.3\% versus $28.6 \%){ }^{92}$

For the important outcome of willingness to perform CPR, we found very-low-quality evidence (downgraded for very serious risk of bias, very serious indirectness, and serious imprecision) from 1 randomized trial documenting that family members of hospitalized adults who were given a compression-only CPR training kit were more likely to express willingness to perform CPR (34\%) than family members given a conventional CPR training kit, but this difference did not achieve statistical significance (28\%; OR, 1.30; 95\% CI, $0.85-1.98) .^{71}$

\section{Treatment Recommendation}

We suggest that communities may train bystanders in compression-only $\mathrm{CPR}$ for adult $\mathrm{OHCA}$ as an alternative to training in conventional CPR (weak recommendation, verylow-quality evidence).

\section{Values, Preferences, and Task Force Insights}

In making this recommendation, we took into account that willingness to perform bystander CPR in the community may be increased when compression-only CPR is offered as an alternative technique. ${ }^{94-97}$

Accordingly, communities should consider existing bystander CPR rates and other factors, such as local epidemiology of OHCA and cultural preferences, when deciding on the optimal community CPR training strategy.

Compression-only CPR instruction has been proposed for several reasons, including overcoming barriers to providing $\mathrm{CPR}$, simplicity in delivery so that all lay providers are able to provide CPR, ease of instruction, etc. Recognizing that a proportion of cardiac arrests are caused by asphyxia (eg, drowning or with cardiac arrests involving children) and in these cases compression-only CPR may not be as effective as conventional CPR, the EIT Task Force suggests that communities consider epidemiology of cardiac arrest in their locale, their bystander CPR response rates, and cultural preferences along with this systematic review to decide on their optimal community CPR training strategy.

\section{Knowledge Gaps}

- Studies with patient survival outcomes and bystander CPR rates are needed.

\section{Advanced Life Support Training}

ALS training was established in the mid-1970s. Since this time, the courses have evolved in design and have been implemented in many different countries, training healthcare workers throughout the world. Unfortunately, the literature suggests that without ongoing education the skills learned in these courses are lost over a period of months. ${ }^{17,98}$ There are also increasing pressures from administrators to justify the time and costs of training away from the clinical workplace.

This section addresses issues associated with ALS training and key PICO questions that could supplement learning and retention of resuscitation skills. If effective and transferable to the clinical environment, these interventions have the potential to improve healthcare worker performance and help save lives.

The questions reviewed include

- The use of precourse preparation to determine if it improves learning and clinical performance (EIT 637)

- The use of high-fidelity manikins (EIT 623)

- The effect of leadership and team training (EIT 631)

- Determine if there is any evidence for an alternate retraining interval to affect learning and performance of healthcare workers (EIT 633) 


\section{Precourse Preparation for Advanced Life Support Courses (EIT 637)}

Among students who are taking ALS courses in an educational setting $(\mathrm{P})$, does inclusion of specific precourse preparation (eg, eLearning and pretesting) (I), compared with no such preparation $(\mathrm{C})$, change survival rates, skill performance in actual resuscitations, cognitive knowledge, skill performance at course conclusion, skill performance at 1 year, skill performance at time between course conclusion and 1 year $(\mathrm{O})$ ?

\section{Consensus on Science}

For the important outcomes of skill performance at course conclusion and cognitive knowledge, we identified moderate-quality evidence (downgraded for indirectness) from 1 RCT enrolling a total of 572 participants showing no benefit for 1 specific format of precourse preparation (skill: mean difference, -0.5 ; $95 \% \mathrm{CI},-2.81$ to 1.81 ; knowledge: difference in pass rates, $1.8 \% ; P=0.4){ }^{98 a}$ The study did not evaluate the impact of precourse preparation on face-to-face or overall course time (eg, when used as part of a blended learning program).

\section{Treatment Recommendation}

The confidence in effect estimates is so low that the task force decided a specific recommendation for or against precourse preparation in ALS courses was too speculative.

\section{Values, Preferences, and Task Force Insights}

There is considerable ambiguity about the definition of precourse learning, particularly because some larger published studies have used a blended learning model (independent electronic learning coupled with a reduced-duration face-toface course) resulting in similar learning outcomes and substantial cost savings. In the end, the EIT Task Force decided to focus purely on precourse preparation and remove studies with hybrid training programs.

\section{Knowledge Gaps}

- There is a need for more research in this area, in particular precourse preparation with limited-resource requirements.

- This research needs to be conducted across various groups. Studies could include different courses, different course participant groups (eg, physicians, nurses, EMTs), and different precourse preparation methodologies (eg, manuals, testing, self-directed learning).

\section{High-Fidelity Manikins in Training (EIT 623)}

Among participants undertaking ALS training in an education setting $(\mathrm{P})$, does the use of high-fidelity manikins (I), compared with the use of low-fidelity manikins (C), change patient outcomes, skill performance in actual resuscitations, skill performance at 1 year, skill performance at time between course conclusion and 1 year, skill performance at course conclusion, cognitive knowledge $(\mathrm{O})$ ?

\section{Consensus on Science}

For the important outcome of skill performance at 1 year, we identified low-quality evidence (downgraded for very serious risk of bias) from $1 \mathrm{RCT}$ enrolling a total of 86 participants showing no benefit for high-fidelity training compared with low-fidelity training (standardized mean difference [SMD], 0; 95\% CI, -0.42 to 0.42$).{ }^{99}$

For the important outcome of skill performance between course conclusion and 1 year, we identified very-low-quality evidence (downgraded for risk of bias and imprecision) from 1 RCT enrolling a total of 47 participants showing no benefit for high-fidelity training compared with low-fidelity training (SMD, 0.08; 95\% CI, -0.49 to 0.65 ). ${ }^{100}$

For the important outcome of skill performance at course conclusion, we identified very-low-quality evidence (downgraded for risk of bias, inconsistency and imprecision) from 12 RCTs, enrolling a total of 726 participants showing a moderate benefit for high-fidelity training compared with lowfidelity training (SMD, 0.60; 95\% CI, 0.17-1.03)..$^{99-110}$ This was supported by very-low-quality evidence (downgraded for inconsistency and imprecision) from 1 non-RCT enrolling a total of 34 participants, which trended in the same direction (SMD, $0.50 ; 95 \% \mathrm{CI},-0.19$ to 1.18$).{ }^{111}$

For the important outcome of knowledge at course conclusion, we identified low-quality evidence (downgraded for risk of bias and imprecision) from 8 RCTs enrolling a total of 773 participants showing no benefit for high-fidelity training compared with low-fidelity training (SMD, 0.15; 95\% CI, -0.05 to 0.34$){ }^{100-103,108,109,112,113}$ This was supported by very-low-quality evidence (downgraded for inconsistency and imprecision) from 1 non-RCT enrolling a total of 34 participants showing no benefit for high-fidelity training (SMD, 0.26 ; $95 \% \mathrm{CI},-0.42$ to 0.93$).{ }^{111}$

\section{Treatment Recommendations}

We suggest the use of high-fidelity manikins when training centers/organizations have the infrastructure, trained personnel, and resources to maintain the program (weak recommendations based on very-low-quality evidence).

If high-fidelity manikins are not available, we suggest that the use of low-fidelity manikins is acceptable for standard ALS training in an educational setting (weak recommendations based on low-quality evidence).

\section{Values, Preferences, and Task Force Insights}

In making these recommendations, we took into account the well-documented, self-reported participant preference for high-fidelity manikins (versus low-fidelity manikins) and the likely impact of this preference on willingness to train. ${ }^{98} \mathrm{We}$ considered the positive impact of skill acquisition at course completion, as well as the lack of evidence of sustained impact on the learner. We also considered the relative costs of high- versus low-fidelity manikins.

High-fidelity manikins can provide physical findings, display vital signs, physiologically respond to interventions (via computer interface), and enable procedures to be performed on them (eg, bag-mask ventilation, intubation, intravenous cannulation). ${ }^{114}$ When considering physical realism, these high-fidelity manikins are more expensive but are increasingly more popular with candidates and faculty.

Determining the treatment recommendation for this PICO question was challenging because of the marginal benefits for the intervention. In reviewing the science, it was clear that there was a benefit to high-fidelity manikins but 
less clear whether the incremental costs justified the added expenses.

\section{Knowledge Gaps}

Future research should

- Explore methods for teaching resuscitation educators how to optimally use high-fidelity simulation to enhance educational outcomes

- Determine the effect of the various different aspects of fidelity (manikin, environment, emotional engagement, etc) on educational outcomes

- Determine the relative importance of debriefing in simulation-based education for ALS courses

- Assess the impact on clinical outcomes and measure performance outcomes extending beyond the end of the course

- Include adequately powered RCTs with sufficient sample size to detect the desired effect in each of the key outcomes

\section{Team and Leadership Training (EIT 631)}

Among students who are taking ALS courses in an educational setting $(\mathrm{P})$, does inclusion of specific leadership or team training (I), compared with no such specific training (C), change patient outcomes, bystander CPR performance, skill performance in actual resuscitations, skill performance at 1 year, skill performance at course conclusion, cognitive knowledge $(\mathrm{O})$ ?

\section{Consensus on Science}

For the critical outcome of patient survival, we found no randomized clinical trials but found very-low-quality evidence (downgraded for risk of bias and indirectness) from 2 observational studies. ${ }^{115,116}$ One study documented an increase in hospital survival from pediatric cardiac arrest over a 4-year period after implementation of a hospital-wide mock code program, which included team training. ${ }^{115}$ The other study documented reduced severity-adjusted surgical mortality in 74 hospitals in the United States that had implemented a surgical team training program, compared with 34 hospitals that had not introduced such a program. ${ }^{116}$

For the critical outcome of skill performance in actual resuscitation, we found very-low-quality evidence (downgraded for risk of bias, indirectness, and imprecision) from a single RCT that randomly assigned 32 internal medicine residents to receive simulation training with a focus on the role of the resuscitation team leader versus no additional training; there was no effect on CPR quality during actual resuscitation of patients. ${ }^{117}$ We also found very-lowquality evidence (downgraded for risk of bias, inconsistency, indirectness, and imprecision) from 2 observational studies. ${ }^{118,119}$

For the important outcome of skill performance at 4 months to 1 year (patient tasks), we found very-low-quality evidence (downgraded for risk of bias, inconsistency, and imprecision) from 2 randomized trials ${ }^{110,120}$ that showed that team or leadership training improved CPR hands-on time and time to initiation of various patient tasks at follow-up assessment.
For the important outcome of skill performance at 4 months to 1 year (teamwork performance), we found lowquality evidence (downgraded for bias and imprecision) from a single randomized trial ${ }^{110}$ and very-low-quality evidence (downgraded for risk of bias) from a single observational study $^{121}$ that showed more frequent teamwork behaviors demonstrated in the teamwork-trained learners at follow-up assessment.

For the important outcome of skill performance at 4 months to 1 year (leader performance), we found moderatequality evidence (downgraded for risk of bias) from a single randomized trial ${ }^{120}$ and very-low-quality evidence (downgraded for risk of bias and imprecision) from a single observational study ${ }^{122}$ that showed more frequent leadership behaviors demonstrated in the leadership-trained learners at follow-up assessment.

For the important outcome of skill performance at course conclusion (patient tasks) (assessed with time to completion of various patient tasks), we found low-quality evidence (downgraded for risk of bias and imprecision) from 8 randomized trials ${ }^{110,120,123-128}$ and very-low-quality evidence (downgraded for risk of bias and indirectness) from 4 observational studies ${ }^{128-131}$ that showed that team or leadership training improved CPR hands-on time and time to initiation of various patient tasks at course conclusion. A dose-response gradient was found.

For the important outcome of skill performance at course conclusion (teamwork performance) (assessed with teamwork score), we found low-quality evidence (downgraded for risk of bias and imprecision) from 6 randomized studies ${ }^{110,123-125,127,132}$ and very-low-quality evidence (downgraded for risk of bias, indirectness, inconsistency, and imprecision) from 3 observational studies ${ }^{121,130,133}$ that showed that teamwork-trained learners demonstrated more frequent teamwork behaviors at course conclusion.

For the important outcome of skill performance at course conclusion (leader performance), we found low-quality evidence (downgraded for risk of bias and imprecision) from 4 randomized studies ${ }^{120,126,128,134}$ and very-low-quality evidence (downgraded for indirectness and imprecision) from 2 observational studies ${ }^{122,131}$ that showed that leadership-trained learners demonstrated more frequent leadership behaviors at course conclusion.

For the important outcome of cognitive knowledge, we found no evidence.

\section{Treatment Recommendations}

We suggest that team and leadership training be included as part of ALS training for healthcare providers (weak recommendation, low-quality evidence).

\section{Values, Preferences, and Task Force Insights}

In making this recommendation, we have placed emphasis on the potential benefit, lack of harm, and high level of acceptance of team and leadership training and lesser value on associated costs.

There are many ways that leadership and team behavior training can be delivered. As such, there was considerable heterogeneity in the studies analyzed. It was recognized that there are multiple variables other than direct instruction on 
a life support course that contribute to the development of leadership skills. There are numerous studies from outside the medical literature that could have been included, but these were considered not to be directly relevant to the PICO.

\section{Knowledge Gaps}

- Studies relating team and leadership training to patient outcome are lacking.

\section{Timing for Advanced Resuscitation Training (EIT 633)}

Among students who are taking ALS courses in an educational setting $(\mathrm{P})$, does any specific interval for update or retraining (I), compared with standard practice (ie, 12 or 24 monthly) (C), change/improve patient outcomes, skill performance in actual resuscitations, skill performance between course completion and 1 year; skill performance at 1 year, skill performance at course conclusion, cognitive knowledge $(\mathrm{O})$ ?

\section{Consensus on Science}

For the important outcome of skill performance at 1 year, there were 4 studies ${ }^{135-138}$ using a variety of refresher techniques and unique outcome measures.

The refreshers included a simulation-enhanced booster 7 to 9 months after the course, a commercially available eLearning tool used monthly, mail-outs of information related to course objectives or a patient management problem every 3 months, or in situ monthly simulation for 6 months. The outcome measures respectively used in the 4 studies were a validated procedural skills and teamwork behavior assessment tool; a previously validated composite score of a written test and cardiac arrest simulation test (CASTest); mock arrest, compression, and ventilation performance with no evidence provided of validity/reliability of the tools; and the change in score on the previously validated Clinical Performance Tool (CPT) and Behavioral Assessment Tool (BAT).

One study used simulation boosters and demonstrated benefit from the refresher in procedural skills and teamwork behavior scores (very-low-quality evidence, downgraded for indirectness and imprecision). ${ }^{138}$ The studies that used periodic eLearning and mailings (very-low-quality evidence, downgraded for indirectness and imprecision) demonstrated no benefit from the refreshers except in the performance on mock arrests. Only 1 of the studies related directly to the research question comparing frequent refreshers to standard retraining intervals, using manikin-based simulation ${ }^{137}$; this study documented better scores on the CPT and equivalent outcomes for the BAT while using less total time of retraining: 4.5 versus 7.5 hours (low-quality evidence, downgraded for imprecision).

For the important outcome of skill performance beyond course completion and before 1 year, there was 1 study that compared a single refresher using video and self-guided practice or a single 2-hour hands-on session with no retraining ${ }^{139}$; it showed no benefit for the refresher (very-low-quality evidence, downgraded for serious bias, indirectness, and imprecision).

For the important outcome of knowledge, there were 4 studies ${ }^{135,138,139,139 a}$ using a variety of refresher techniques, such as simulation-enhanced booster, video and self-guided practice, knowledge examination, and mock resuscitation training or mail-outs as described above. The assessment tools varied from those with no reported validity/reliability evidence to well-described psychometrics in 1 study. ${ }^{139}$ a There was no benefit of refresher training (very-low-quality evidence, downgraded for serious bias, indirectness, and imprecision).

\section{Treatment Recommendation}

Compared with standard retraining intervals of 12 to 24 months, we suggest that more frequent manikin-based refresher training for students of ALS courses may be better to maintain competence (weak recommendation, very-lowquality evidence). The optimal frequency and duration of this retraining is yet to be determined.

\section{Values, Preferences, and Task Force Insights}

In making this recommendation, we consider the rapid decay in skills after standard ALS training to be of concern for patient care. Refresher training, in the form of frequent low-dose in situ training using manikins, offers promise. ${ }^{137}$ The potential cost savings of integrating these sessions into daily workflow rather than removing staff for standard refresher training may be important, as might a reduced total time of retraining. More recent literature in resuscitation demonstrates improved learning from "frequent, low-dose" compared with "comprehensive, all-at-once" instruction and a learner preference for this format. ${ }^{140}$

Ultimately, the question to be asked is, how frequently should training be delivered? As yet, there is no definitive answer to this question because it is dependent on the type of training. For example, it has been shown in another systematic review (EIT 623) that the use of different types of manikins can lead to improved outcomes in the short term. However, there is a paucity of published literature, so there was no consensus within the task force about an overall specified time interval.

\section{Knowledge Gaps}

- To date, studies addressing this PICO question are of relatively poor quality and limited in sample size, without the use of consistent high-quality assessment tools.

- Larger, multicenter studies might be important to answer this important educational question, particularly to determine optimal retraining time periods and costeffectiveness of this model.

- Can initial spaced instruction alter the decay of ALS skills?

- What is the relationship between clinical exposure and skill maintenance?

\section{Implementation}

The resuscitation literature is heterogeneous in its methods, quality, and results. Studies conducted decades apart or in different settings often demonstrate conflicting findings, making comparisons difficult; yet resuscitation councils are required to develop evidence-based guidelines for organizations to implement. Past guideline rollouts have demonstrated that implementation is neither easy nor straightforward and 
can take years to accomplish. ${ }^{141}$ The barriers to implementing a guideline within an organization may delay its entry into practice by years, and modifying caregiver behaviors can take years longer. ${ }^{141-143}$ Recognizing this, publishing clinical practice guidelines is not sufficient without including a discussion of how to implement them.

\section{Implementation: What We Should Do Versus What We Say We Will Do}

It remains unclear which strategies best translate knowledge into practice. Several barriers delayed implementation of the 2005 resuscitation guidelines among member organizations of the Resuscitation Outcomes Consortium, including delays in training providers, obtaining training materials and instructors, reprogramming defibrillators, changing regulatory frameworks, obtaining agreement from physician leadership, and conflicting research interests. ${ }^{143}$ Similar delays were also demonstrated in Europe. ${ }^{142}$

This section addresses issues associated with systems of care for managing cardiac arrest both in- and out- of the hospital; the use of evolving technologies to implement resuscitation; and the use of feedback at the training, individual patient, and systems levels. The section is also premised on the belief that resuscitation outcomes will improve if guideline-based care is implemented and that measurement of actual performance is a necessary component of resuscitation system improvement.

The questions reviewed include

- Implementation of guidelines in communities (EIT 641)

- Cardiac arrest centers (EIT 624)

- Social media technologies (EIT 878)

- Measuring performance of resuscitation systems (EIT 640)

- CPR feedback devices in training (EIT 648)

- Debriefing of resuscitation performance (EIT 645)

- MET for adults (EIT 638)

\section{Implementation of Guidelines in Communities (EIT 641)}

Within organizations that provide care for patients in cardiac arrest in any setting $(\mathrm{P})$, does implementation of resuscitation guidelines (I), compared with no such use (C), change survival to 180 days with good neurologic outcome, survival to hospital discharge, bystander CPR performance, ROSC (O)?

\section{Consensus on Science}

For the critical outcome of survival to 180 days with good neurologic outcome, we found no data.

For the critical outcome of survival to hospital discharge, we identified very-low-quality evidence (downgraded for imprecision, risk of bias, and indirectness) from 11 observational studies. Seven studies showed that implementation of resuscitation guidelines improved survival (RR, 1.25; 95\% CI, 1.16-1.35), ${ }^{14-150}$ and 4 studies were neutral. ${ }^{141,142,151,152}$

For the important outcome of ROSC, we identified verylow-quality evidence (downgraded for imprecision, risk of bias, and indirectness) from 10 observational studies. Seven studies showed that implementation of resuscitation guidelines improved ROSC (RR, 1.15; 95\% CI, 1.11-1.20), ${ }^{144-150}$ and 3 studies were neutral. ${ }^{142,151,152}$

For the important outcome of CPR performance, we identified very-low-quality evidence (downgraded for imprecision, risk of bias, and indirectness) from 4 observational studies that implementation of resuscitation guidelines improved the hands-off ratio of emergency medical services CPR performance (mean 0.28 versus 0.42 ). ${ }^{142,145,149,150}$

\section{Treatment Recommendations}

We recommend implementation of resuscitation guidelines within organizations that provide care for patients in cardiac arrest in any setting (strong recommendation, very-low-quality evidence).

\section{Values, Preferences, and Task Force Insights}

In making this (discordant) recommendation, we placed a high value on the notion that cardiac arrest care requires coordination of time-sensitive interventions and often involves care providers who have not worked together before, potentially from multiple agencies or departments; guidelines may facilitate coordinated action. Despite the very low quality of evidence, the direction of effect is consistent, and pooled data are statistically significant and clinically meaningful. A discordant recommendation is justified because cardiac arrest is life threatening and the likelihood of benefit is high relative to possible harm. ${ }^{153}$ We recognize that most of the authors of the 2015 CoSTR are involved in writing resuscitation guidelines and that this should be considered a potential intellectual conflict of interest.

\section{Knowledge Gaps}

- The optimal treatment components of resuscitation guidelines are unknown.

- The optimal methods for knowledge translation are unknown.

- The optimal methods for implementation are unknown.

\section{Cardiac Arrest Centers (EIT 624)}

Adults and children in OHCA (P), does transport to a specialist cardiac arrest center (I), compared with no directed transport (C), change neurologically intact survival at 30 days, survival to hospital discharge with good neurologic outcome, survival to hospital discharge, hospital admission, ROSC (O)?

\section{Consensus on Science}

There were no RCTs identified that specifically addressed this question. Of the 26 observational studies included in the evidence review, there was only 1 prospective study where survival outcomes in OHCA patients transported to a critical care medical center were compared with those transported to a non-critical care hospital. ${ }^{154}$ There were 10 observational studies that compared OHCA patient survival outcomes between hospitals based on various hospital characteristics such as hospital type, hospital size, hospital location, and OHCA case volume. ${ }^{155-164} \mathrm{Six}$ observational studies compared OHCA patient survival outcomes before and after the implementation of a regionalized system of postresuscitation care. ${ }^{165-170}$ Six observational studies compared patient 
survival outcomes based on transport time to the hospital and/or direct versus indirect transport to a major center. ${ }^{171-176}$ One observational study compared OHCA patient outcomes across hospitals in those patients who received early coronary angiography or reperfusion and induced hypothermia versus those who did not. ${ }^{156}$ Two observational studies did not report any of the patient survival outcomes of interest and hence do not appear in the summary below. ${ }^{177,178}$ Heterogeneity in study design and inclusion criteria precluded meta-analyses.

For the critical outcome of neurologically intact survival, we have identified very-low-quality evidence (downgraded for significant risk of bias and indirectness) from 12 observational studies enrolling more than 23000 patients. ${ }^{154,156,158,163,165,167-170,172-174}$ Three studies examined neurologic intact survival at 30 days..$^{154,170,173}$ The other 9 studies reported survival to hospital discharge with good neurologic outcome. ${ }^{156,158,163,165,167-169,172,174,178 \text { a }}$ There was an association between improved neurologic intact survival and patient transport to specialist cardiac arrest centers. The key study reported improved 30-day neurologically favorable survival (Cerebral Performance Category $\leq 2$ ) in OHCA patients transported to a critical care medical center compared with a non-critical care hospital (6.7\% versus 2.8\%; OR, 2.47; 95\% CI, 2.02-3.01; $P<0.001) .{ }^{154}$

For the important outcome of survival, we identified very-low-quality evidence (downgraded for significant risk of bias and indirectness, with heterogeneity in reported hospital factors associated with differences in patient survival) from 21 studies with more than 120000 patients. Three studies examined survival at 30 days, ${ }^{159,161,173} 18$ studies with more than 120000 patients reported survival to hospital discharge, ${ }^{155-160,163,164,166,168-172,174-176}$ and 1 study reported survival at 4.6 years. ${ }^{162}$

There was an association with survival and transport to a cardiac arrest center; however, the specific hospital factors most related to patient outcome were inconsistent in these studies.

\section{Treatment Recommendation}

We suggest that OHCA patients should be considered for transport to a specialist cardiac arrest center as part of wider regional system of care for management of patients with OHCA (weak recommendation, low-quality evidence).

\section{Values, Preferences, and Task Force Insights}

In making this recommendation, we recognize the development of cardiac arrest centers may be considered as a health improvement initiative, as has been performed for other critical conditions, including myocardial infarction, stroke, and major trauma, without the evidence of randomized trials.

\section{Knowledge Gaps}

- What are the precise differences in postresuscitation care received at cardiac arrest centers compared with noncardiac arrest centers?

- The safe journey time or distance for patient transport under various conditions is unknown.

- The essential treatments that a cardiac resuscitation center should offer need to be defined.
- What is the role of secondary transport from receiving hospital to a regional center?

- Is there sufficient clinical equipoise to conduct an RCT of standard care versus transport to a cardiac resuscitation center?

\section{Social Media Technologies (EIT 878)}

For OHCA (P), does having a citizen CPR responder notified of the event via technology or social media (I), compared with no such notification (C), change survival to hospital discharge with good neurologic outcome, survival to hospital discharge, hospital admission, ROSC, bystander CPR rates, time to first compressions $(\mathrm{O})$ ?

\section{Consensus on Science}

We did not identify any evidence to address the critical outcomes. We identified 1 RCT that addressed the important outcome of bystander CPR rates.

For the outcome of bystander CPR rates, we identified high-quality evidence from $1 \mathrm{RCT}^{178 \mathrm{~b}}$ involving a mobilephone positioning system which alerted lay responders within $500 \mathrm{~m}$ of a suspected $\mathrm{OHCA}$, demonstrating a rate of bystander-initiated CPR of $62 \%$ (188 of 305 patients) in the intervention group versus a rate of $48 \%$ (172 of 360 patients) in a control group which did not receive such alerts, with an absolute difference of $14 \%$ (95\% CI, 6-21; $P<0.001)$.

For the outcome of time to first shock, we identified very-low-quality evidence (downgraded for risk of bias and indirectness) from 1 case series $(n=76)$ involving text-message alerts to lay responders within $1000 \mathrm{~m}$ of a suspected cardiac arrest demonstrating a median call to first shock time of 8 minutes (interquartile range, 6:35-9:49 minutes). ${ }^{179}$ In the same study, the median time from call to first shock when emergency medical services personnel arrived first was 10:39 minutes (interquartile range, 8:18-13:23 minutes).

For the outcome of first responder on scene, we identified very-low-quality evidence (downgraded for risk of bias and indirectness) from 1 case series involving computergenerated phone calls and text messages to lay responders within $500 \mathrm{~m}$ of a suspected cardiac arrest, demonstrating that responders notified via this system arrived first in $44.6 \%$ of suspected cardiac arrest episodes, compared with emergency medical services providers in $55.4 \%$ of the episodes. ${ }^{180}$

\section{Treatment Recommendation}

We suggest that individuals in close proximity to suspected OHCA episodes who are willing and able to perform CPR be notified of the event via technology or social media (weak recommendation, moderate-quality evidence).

\section{Values, Preferences, and Task Force Insights}

In making this recommendation, we place value on the timesensitive benefit of CPR and AED use in OHCA and the limitations of optimized emergency medical services systems to improve response times. We also recognize that there are individuals willing and able to provide BLS in most communities and these novel technologies can engage these individuals in the response to cardiac arrest outside the hospital. Although the evidence available to support this treatment recommendation is sparse, the relative benefits versus harms are judged to 
be in favor of the recommendation. Research into the effectiveness of these interventions is justified and required.

\section{Knowledge Gaps}

- What is the impact of notified versus unnotified bystander responses on clinically meaningful patient outcomes such as survival to hospital discharge with good neurologic outcome, survival to hospital discharge, survival to hospital admission, and ROSC?

- What is the impact of notified versus unnotified bystander responses on bystander CPR rates and time to first compressions?

\section{Measuring Performance of Resuscitation Systems (EIT 640)}

Among resuscitation systems caring for patients in cardiac arrest in any setting $(\mathrm{P})$, does a performance measurement system (I), compared with no system (C), change survival to hospital discharge, skill performance in actual resuscitations, survival to admission, system-level variables $(\mathrm{O})$ ?

\section{Consensus on Science}

For the critical outcome survival to hospital dischargeOHCA, we identified very-low-quality evidence (downgraded for indirectness, imprecision, and inconsistency) from 4 observational studies enrolling 6983 patients. ${ }^{181-184}$ One of these studies contributed a disproportional number of patients (6331). ${ }^{181}$ Heterogeneity prevented calculating a pooled effect and limited our confidence in the individual effects. Individual effects appear weakly in favor of quality measurement.

For the critical outcome of survival to hospital discharge-in-hospital cardiac arrest (IHCA), we identified low-quality evidence (downgraded for indirectness, imprecision, and inconsistency) from 2 observational studies enrolling 318 patients showing no benefit in survival to hospital discharge (data cannot be pooled). ${ }^{185,186}$ One study showed a modest improvement in neurologic outcomes. ${ }^{186}$ There was very-low-quality evidence (downgraded for indirectness, imprecision, and inconsistency) from 3 observational timeseries studies enrolling 105003 patients. ${ }^{187-189}$ One of these studies contributed a disproportional number of patients (104732). ${ }^{187}$ Heterogeneity prevented calculation of a pooled effect. Individual effects were in favor of quality measurement in 2 studies ${ }^{187,188}$ and showed no effect for the third study. ${ }^{189}$

For the important outcome of chest compression depth, we have identified very-low-quality evidence (downgraded for risk of bias and inconsistency) from 3 observational studies enrolling 990 patients. ${ }^{182,185,186}$ Heterogeneity prevented calculating a pooled effect and limited our confidence in the individual effects. Individual effects appear weakly in favor of quality measurement.

For the important outcome of chest compression rate, we identified very-low-quality evidence (downgraded for risk of bias and inconsistency) from 6 observational studies, enrolling 1020 patients in 4 of the studies, and an unreported number in 2 others. ${ }^{182-186,189}$ Heterogeneity prevented calculating a pooled effect and limited our confidence in the individual effects. Three of the studies appear to weakly favor quality measurement, whereas 3 showed no effect.
For the important outcome of other system variables, very-low-quality evidence (downgraded for risk of bias, indirectness) from 1 human observational study shows defibrillator-equipped resource response time decreased to 5.3 minutes from 6.7 minutes when an optimization strategy was implemented. ${ }^{181}$ Across studies, the direction of the effect was consistent, and at times the effect size was large and statistically significant. There is no evidence that data collection and feedback are deleterious to patients in any way.

\section{Treatment Recommendation}

We suggest the use of performance measurement and quality improvement initiatives in organizations that treat cardiac arrest (weak recommendation, very-low-quality evidence).

\section{Values, Preferences, and Task Force Insights}

In making this recommendation, we place greater value on the potential for lives saved and the idea that you can only improve what you can measure, and lesser value on the costs associated with performance measurement and quality improvement interventions.

Once new guidelines have been approved and frontline providers trained, their real-life integration is often overlooked. Assessing clinical performance and using a system to continuously assess and improve quality can improve compliance with guidelines.

\section{Knowledge Gaps}

There is a need to

- Identify the most appropriate approach to measure performance

- Better understand the influence of local community and organizational characteristics

\section{CPR Feedback Devices in Training (EIT 648)}

Among students who are taking BLS or ALS courses in an educational setting (P), does CPR feedback device use (I), compared with no use of CPR feedback devices (C), change/ improve patient outcomes, skill performance in actual resuscitations, skill performance at 1 year, skill performance at course conclusion, cognitive knowledge (O)?

\section{Consensus on Science}

For the critical outcomes of improvement of patient outcomes and skill performance at actual resuscitation, we found no evidence that examined the use of feedback devices.

For the important outcome of skill performance at 1 year, we found 5 studies (low-quality evidence downgraded for imprecision, inconsistency, and risk of bias) that retested subjects after a period of time (6 weeks to 12 months) and showed substantial decay in skills irrespective of whether a feedback device was used. ${ }^{50,191,192,211,214}$ Meta-analysis was not possible.

For the important outcome of skill performance at course conclusion, we found 28 low-quality studies (downgraded for risk of bias, imprecision, and indirectness) that demonstrated some limited improvement in CPR quality ${ }^{50,191-217}$ Compression depth, compression rate, chest recoil, hand placement, hands-off time, and ventilation were used as 
markers of CPR quality. Heterogeneous reporting prevented some meta-analyses.

There were 23 directive feedback studies ${ }^{50,191-207,212-216}$ showing that in comparison with no feedback devices, the use of feedback devices

- Had no effect on mean depth (SMD, $-0.10 ; 95 \%$ CI, -0.58 to $0.39 ; P=0.70$ ).

- Increased the number of participants able to compress to the correct depth $(\mathrm{OR}, 3.47 ; 95 \%$ CI, $2.55-4.73 ; P<0.001)$.

- Was associated with a compression rate closer to $100 /$ min, and increased number of subjects compressed at the correct rate (OR, 4.10; 95\% CI, 2.81-6.00; $P<0.001)$.

- Volume and rate of ventilations improved in the majority of studies.

- Hand placement was not shown to improve $(1.38 ; 95 \%$ CI, $0.88-2.15 ; P=0.16)$, but recoil was (OR, $1.63 ; 95 \%$ CI, $1.10-2.42 ; P=0.02$ ).

Five tonal guidance studies improved compression rate (OR, 1.72; 95\% CI, 1.13-2.64; $P=0.01){ }^{208-211,217}$ One study showed statistically significantly reduced mean compression depth, but this may not be clinically significant $(39.3 \pm 9.5 \mathrm{~mm}$ to $35.8 \pm 8.2 \mathrm{~mm} ; P<0.01){ }^{208}$ Two other studies showed a nonsignificant increase in the proportion of participants unable to perform compressions to adequate depth (OR, 1.23; 95\% CI, 0.87-1.74; $P=0.24){ }^{209,210}$ Two neonatal studies showed improved compliance with chest compression rates and manual inflation rates, but results were limited to certain pieces of music ("Radetzkymarsch"211 and ABBA's "SOS"217).

For the important outcome of improvement of cognitive knowledge, we found no evidence that examined the use of feedback devices.

\section{Treatment Recommendation}

We suggest the use of feedback devices that provide directive feedback on compression rate, depth, release, and hand position during training (weak recommendation, low-quality evidence). If feedback devices are not available, we suggest the use of tonal guidance (examples include music or metronome) during training to improve compression rate only (weak recommendation, low-quality evidence).

\section{Values, Preferences, and Task Force Insights}

Unfortunately, several of the tonal studies identified compression depth decreasing as the participant focused on the rate. The positive effect of real-time feedback devices on CPR performance was found only at the end of training.

In making these recommendations, a higher value was placed on the potential of improving CPR performance over the potential costs. Used by BLS instructors, these real-time feedback adjuncts can provide accurate participant performance information to give effective feedback during training. ${ }^{202}$

Real-time directive feedback devices provide immediate feedback on performance, including depth, rate, hand placement, and release. Guidance feedback devices are tonal devices that only prompt rate.

\section{Knowledge Gaps}

- The effectiveness of different types of feedback is unknown.
- What is the role of instructors in combination with the use of real-time feedback devices?

- The effect of real-time feedback on performance of ventilations (currently limited by available technology) is unknown.

- The effect of real-time feedback on psychomotor skill retention, attainment of cognitive knowledge, performance in actual resuscitations, and patient outcomes is unknown.

\section{Debriefing of Resuscitation Performance (EIT 645)}

Among rescuers who are caring for patients in cardiac arrest in any setting $(\mathrm{P})$, does briefing or debriefing (I), compared with no briefing or debriefing (C), change survival, skill performance in actual resuscitations, improve quality of resuscitation (eg, reduce hands-off time), cognitive knowledge $(\mathrm{O})$ ?

\section{Consensus on Science}

There were no RCTs and no studies comparing briefing as the sole intervention. Data from 2 in-hospital observational beforeafter studies, 1 in adults ${ }^{185}$ and 1 in pediatrics, ${ }^{186}$ involving a total 318 patients and 2494 epochs of chest compressions demonstrate improved outcomes after implementation of a data-driven, performance-focused debriefing program for resuscitation team members using CPR-quality defibrillator transcripts.

For the critical outcome of survival with favorable neurologic outcome at discharge in in-hospital cardiac arrest (IHCA), very-low-quality data (downgraded for imprecision) demonstrated an improvement with debriefing from $28.8 \%$ to $50.0 \%$ (RR, 1.73 ; 95\% CI, 1.04-2.43).

For the critical outcome of survival to hospital discharge, very-low-quality evidence (downgraded for inconsistency) yielded an insignificant improvement from $17 \%$ to $18.8 \%$ (RR, 1.35 ; 95\% CI, 0.81-2.1).

For the critical outcome of ROSC, low-quality evidence associated the intervention with an increase of $54.7 \%$ to $66.5 \%$ (RR, 1.25 ; 95\% CI, 1.06-1.41).

For the critical outcomes of compression depth and compression rate within target range, moderate-quality data (upgraded for strong association) demonstrated an improvement for both (RR, 1.18; 95\% CI, 1.15-1.21 and RR, 1.25; $95 \%$ CI, 1.21-1.29, respectively).

For these same outcomes in the out-of-hospital setting, the quality of evidence was further downgraded for indirectness, resulting in very-low-quality evidence for the 3 survival outcomes and low-quality evidence for the 2 process outcomes.

\section{Treatment Recommendations}

We recommend data-driven, performance-focused debriefing of rescuers after IHCA in both adults and children (strong recommendation, low-quality evidence). We suggest data-driven, performance-focused debriefing of rescuers after OHCA in both adults and children (weak recommendation, very-lowquality evidence).

\section{Values, Preferences, and Task Force Insights}

In making the discordant recommendation for IHCA, we have placed a high value on the consistency and precision of the improvement in CPR quality and short-term survival as the proximal end points of the educational intervention. 
We have placed a lesser value on the potential costs of implementation.

\section{Knowledge Gaps}

- The benefit of data-driven, performance-focused debriefing for OHCA is unknown.

- The ideal format in which data-driven, performancefocused debriefing is delivered is unknown.

- The proper source of objective data for data-driven, performance-focused debriefing (eg, CPR-quality transcript, video) needs to be determined.

- The optimal duration of data-driven, performancefocused debriefing is unknown.

- The most effective interval between event and datadriven, performance-focused debriefing remains to be determined.

\section{Medical Emergency Teams (MET) for Adults (EIT 638)}

Among adults who are at risk for cardiac or respiratory arrest in the hospital (P), does use of the Early Warning Score (EWS)/response teams/MET systems (I), compared with no such responses (C), change survival to hospital discharge, in-hospital incidence of cardiac/respiratory arrest, survival to hospital discharge with good neurologic outcome $(\mathrm{O})$ ?

\section{Consensus on Science}

For the critical outcome of survival to hospital discharge, we have found low-quality evidence (downgraded for risk of bias and inconsistency) from 2 RCTs $^{218,219}$ and very-lowquality evidence (downgraded for risk of bias, inconsistency, and indirectness) from 33 non-RCTs. ${ }^{220-252}$ Of the 2 RCTs, one demonstrated no significant difference between control hospitals (functioned as usual) and intervention hospitals (introduced a MET team) for both unadjusted ( $P=0.564$; Diff, $-0.093 ; 95 \% \mathrm{CI},-0.423$ to 0.237$)$ and adjusted $(P=0.752$; OR, 1.03 ; 95\% CI, 0.84-1.28) survival. ${ }^{218}$ The other study demonstrated a significant difference between control wards and intervention wards (introduction of a critical care outreach service) with all patients (OR, 0.70; 95\% CI, 0.500.97 ), and matched randomized patients (OR, 0.52; 95\% CI, $0.32-0.85) .{ }^{219}$ Of the 33 nonrandomized studies reporting mortality, no studies reported statistically significant worse outcomes for the intervention; 15 studies with no adjustment demonstrated no significant improvement ${ }^{220-234} ; 6$ studies with no adjustment demonstrated significant improvement ${ }^{235-240}$; 1 study with no adjustment reported on rates, which improved with MET, but did not report on significance $^{241} ; 1$ study with no adjustment demonstrated significant improvement for medical patients but not surgical patients (combined significance not reported) ${ }^{242}$; 4 studies with adjustment demonstrated significant improvement both before and after adjustment ${ }^{243,244,250,252}$; 2 studies with adjustment demonstrated no significant improvement both before and after adjustment ${ }^{245,246} ; 2$ studies with adjustment demonstrated significant improvement before adjustment but not after adjustment ${ }^{247,251} ; 1$ study with adjustment demonstrated significant improvement before adjustment but not after adjustment ${ }^{27} ; 1$ study that reported on both unexpected mortality and overall mortality showed significant improvement both before and after adjustment for unexpected mortality but no significant improvement both before and after adjustment for overall mortality ${ }^{249}$; and 1 before-after study that presented "after" data for unexpected mortality in 3 separate time bands demonstrated significant improvement in time band 3 before adjustment and in time bands 2 and 3 after adjustment. ${ }^{248}$ The heterogeneous nature of the studies prevents pooling of data; however, there is a suggestion of improved hospital survival in those hospitals that introduce a MET service, and a suggestion of a dose-response effect, with higher-intensity systems (eg, higher MET calling rates, senior medical staff on MET teams) being more effective.

For the critical outcome of in-hospital incidence of cardiac/ respiratory arrest, we found low-quality evidence (downgraded for risk of bias and indirectness) from $1 \mathrm{RCT}^{218}$ and very-low-quality evidence (downgraded for risk of bias, inconsistency, and indirectness) from 31 further non-RCTs. ${ }^{220,221,224,225,227-230,232-247,249,250,253-256}$ For the $1 \mathrm{RCT},{ }^{218}$ no significant difference between control hospitals and intervention hospitals, both unadjusted $(P=0.306$; Diff, -0.208 ; $95 \% \mathrm{CI},-0.620$ to 0.204$)$ and adjusted $(P=0.736$; OR, $0.94 ; 95 \%$ CI, 0.79-1.13), was demonstrated. Of the 31 observational studies reporting on cardiac arrest rates, 1 before-after study using an aggregated weighted scoring system (Modified Early Warning Score [MEWS]) reported significantly higher cardiac arrest rates in MEWS bands 3 to 4 after intervention, but not in MEWS bands 0 to 2 or 5 to 15 , and overall cardiac arrest rate significance was not reported ${ }^{232} ; 7$ studies with no adjustment demonstrated no significant improvement in cardiac arrest rates after the introduction of a MET system $^{224,225,228-230,233,234} ; 15$ studies with no adjustment demonstrated significant improvement in cardiac arrest rates after the introduction of a MET system $220,221,227,235,236,238,239,241-244,247,253-256$; 5 studies with adjustment demonstrated significant improvement in cardiac arrest rates after the introduction of a MET system both before and after adjustment ${ }^{237,240,250,252,256}$; 1 study with contemporaneous controls demonstrated no significant improvement in cardiac arrest rates after the introduction of a MET system both before and after adjustment ${ }^{246}$; 1 study with adjustment demonstrated significant improvement before adjustment for whole of hospital and non-intensive care unit (ICU) cardiac arrest rates, but only for non-ICU cardiac arrest rates after adjustment ${ }^{245}$; and 1 before-after study that presented "after" unadjusted data for cardiac arrest in 3 separate time bands demonstrated significant improvement in time bands 2 and 3.249 The heterogeneous nature of the studies prevents pooling of data. However, there is a suggestion of a reduced incidence of cardiac/ respiratory arrest in those hospitals that introduce a MET service, and a suggestion of a dose-response effect, with higher-intensity systems (eg, higher MET calling rates, senior medical staff on MET teams) being more effective.

\section{Treatment Recommendations}

We suggest that hospitals consider the introduction of an EWS/response team/MET system to reduce the incidence of IHCA and in-hospital mortality (weak recommendation, lowquality evidence).

\section{Values, Preferences, and Task Force Insights}

This recommendation places a high value on the outcomes - the prevention of IHCA and death-relative to the likely substantial 
cost of the system. Such a system should provide a system of care that includes (a) staff education about the signs of patient deterioration; (b) appropriate and regular vital signs monitoring of patients; (c) clear guidance (eg, via calling criteria or early warning scores) to assist staff in the early detection of patient deterioration; (d) a clear, uniform system of calling for assistance; and (e) a clinical response to calls for assistance. The best method for the delivery of these components is unclear. ${ }^{98}$ The "Recommended Guidelines for Monitoring, Reporting, and Conducting Research on Medical Emergency Team, Outreach, and Rapid Response Systems: An Utstein-Style Scientific Statement"257 should be used by hospitals to collect the most meaningful data to optimize system interventions and improve clinical outcomes.

\section{Knowledge Gaps}

- What are the ideal components of the "afferent limb" of a rapid response system, eg, which vital signs, observations, and/or laboratory parameters, and with what frequency?
- What are the ideal components of an education program in the recognition of a deteriorating patient?

- What is the ideal mechanism for escalation for assistance (eg, conventional escalation versus automated electronic escalation)?

- What is the ideal makeup of the efferent limb (the response team)?

\section{Acknowledgments}

We thank the following individuals (the Education, Implementation, and Teams Chapter Collaborators) for their collaborations on the systematic reviews contained in this section: Janet E. Bray, Jan Breckwoldt, Steven C. Brooks, Adam Cheng, Aaron J. Donoghue, Jonathan P. Duff, Dana P. Edelson, Henrik Fischer, Elaine Gilfoyle, Ming-Ju Hsieh, David A. Kloeck, Patrick Ko, Marion Leary, Theresa M. Olasveengen, Jon C. Rittenberger, Robert D. Schultz, Dion Stub, Zuzana Triska, Traci A. Wolbrink, Chih-Wei Yang, and Joyce Yeung. 


\section{Disclosures}

2015 CoSTR Part 8: Education, Implementation, and Teams: Writing Group Disclosures

\begin{tabular}{|c|c|c|c|c|c|c|c|c|}
\hline $\begin{array}{l}\text { Writing Group } \\
\text { Member }\end{array}$ & Employment & Research Grant & $\begin{array}{c}\text { Other } \\
\text { Research } \\
\text { Support }\end{array}$ & $\begin{array}{c}\text { Speakers' } \\
\text { Bureau/ } \\
\text { Honoraria }\end{array}$ & $\begin{array}{l}\text { Expert } \\
\text { Witness }\end{array}$ & $\begin{array}{l}\text { Ownership } \\
\text { Interest }\end{array}$ & $\begin{array}{l}\text { Consultant/ } \\
\text { Advisory } \\
\text { Board }\end{array}$ & Other \\
\hline Farhan Bhanji & McGill University & None & None & None & None & None & None & None \\
\hline Judith C. Finn & Curtin University & $\begin{array}{c}\text { NHMRC } \\
\text { (Australia) } \dagger\end{array}$ & None & None & None & None & None & None \\
\hline Blair Bigham & $\begin{array}{c}\text { Heart and Stroke Foundation } \\
\text { of Canada }\end{array}$ & None & None & None & None & None & None & None \\
\hline John E. Billi & $\begin{array}{c}\text { The University of Michigan } \\
\text { Medical School }\end{array}$ & None & None & None & None & None & None & None \\
\hline Robert Frengley & $\begin{array}{l}\text { Waikato District } \\
\text { Health Board }\end{array}$ & None & None & None & None & None & None & None \\
\hline Robert Greif & $\begin{array}{c}\text { Universitätsspital } \\
\text { Anesthesiology and Pain } \\
\text { Medicine }\end{array}$ & $\begin{array}{l}\text { Departmental } \\
\text { Grants* }\end{array}$ & None & None & None & None & None & $\begin{array}{l}\text { Journal Trends in } \\
\text { Anesthesia and } \\
\text { Critical Care; Editor } \\
\text { in chief* }\end{array}$ \\
\hline Taku Iwami & $\begin{array}{c}\text { Kyoto University Health } \\
\text { Service }\end{array}$ & None & None & None & None & None & None & None \\
\hline Andrew Lockey & $\begin{array}{c}\text { European Resuscitation } \\
\text { Council }\end{array}$ & None & None & None & None & None & None & None \\
\hline $\begin{array}{l}\text { Matthew } \\
\text { Huei-Ming Ma }\end{array}$ & $\begin{array}{c}\text { National Taiwan University } \\
\text { Hospital }\end{array}$ & None & None & None & None & None & None & None \\
\hline Mary E. Mancini & $\begin{array}{c}\text { The University of Texas at } \\
\text { Arlington }\end{array}$ & $\mathrm{AHRQ}^{*}$ & None & None & None & None & None & None \\
\hline $\begin{array}{l}\text { Mary Ann } \\
\text { McNeil }\end{array}$ & University of Minnesota & None & None & None & None & None & None & None \\
\hline $\begin{array}{l}\text { Koenraad } \\
\text { Monsieurs }\end{array}$ & Antwerp University Hospital & $\begin{array}{l}\text { Zoll Medical*; } \\
\text { Laerdal } \\
\text { Foundation* }\end{array}$ & None & None & None & None & None & None \\
\hline $\begin{array}{l}\text { Vinay M. } \\
\text { Nadkarni }\end{array}$ & $\begin{array}{l}\text { Children's Hospital } \\
\text { Philadelphia }\end{array}$ & $\begin{array}{l}\text { NIH/AHRQ†; } \\
\text { Nihon-Kohden } \\
\text { Corporation*; } \\
\text { Zoll Foundation/ } \\
\text { Corporationt; } \\
\text { Laerdal Medical* }\end{array}$ & None & None & None & None & None & None \\
\hline \multicolumn{9}{|l|}{ Consultant } \\
\hline Eddy Lang & $\begin{array}{l}\text { University of Calgary } \\
\text { Emergency Medicine }\end{array}$ & None & None & None & None & None & $\begin{array}{c}\text { American } \\
\text { Heart } \\
\text { Association† }\end{array}$ & None \\
\hline
\end{tabular}

This table represents the relationships of writing group members that may be perceived as actual or reasonably perceived conflicts of interest as reported on the Disclosure Questionnaire, which all members of the writing group are required to complete and submit. A relationship is considered to be "significant" if (a) the person receives $\$ 10000$ or more during any 12-month period, or $5 \%$ or more of the person's gross income; or (b) the person owns $5 \%$ or more of the voting stock or share of the entity, or owns $\$ 10000$ or more of the fair market value of the entity. A relationship is considered to be "modest" if it is less than "significant" under the preceding definition.

*Modest.

†Significant. 


\section{Appendix}

CoSTR Part 8: PICO Appendix

\begin{tabular}{|c|c|c|c|}
\hline Part & Task Force & PICO ID & Short Title \\
\hline Part 8 & EIT & EIT 623 & $\begin{array}{l}\text { High-Fidelity } \\
\text { Manikins in } \\
\text { Training }\end{array}$ \\
\hline Part 8 & EIT & EIT 624 & $\begin{array}{l}\text { Cardiac Arrest } \\
\text { Centers }\end{array}$ \\
\hline Part 8 & EIT & EIT 628 & $\begin{array}{l}\text { Timing for BLS } \\
\text { Retraining }\end{array}$ \\
\hline Part 8 & EIT & EIT 631 & $\begin{array}{l}\text { Team and } \\
\text { Leadership } \\
\text { Training }\end{array}$ \\
\hline Part 8 & EIT & EIT 633 & $\begin{array}{l}\text { Timing for } \\
\text { Advanced } \\
\text { Resuscitation } \\
\text { Training }\end{array}$ \\
\hline
\end{tabular}

$\begin{array}{ccl}\text { Part } 8 \quad \text { EIT } \quad \text { EIT } 634 & \begin{array}{l}\text { Resource-Limited } \\ \text { Settings }\end{array}\end{array}$

$\begin{array}{lll}\text { Part } 8 \quad \text { EIT } & \text { EIT } 637 & \text { Precourse }\end{array}$ Preparation for Advanced Life Support Courses

$\begin{array}{lll}\text { Part } 8 \quad \text { EIT } \quad \text { EIT } 638 & \text { Medical } \\ & & \text { Emergency Teams } \\ & \text { for Adults }\end{array}$

Part $8 \quad$ EIT $\quad$ EIT $640 \quad$ Measuring Performance of Resuscitation Systems

$\begin{array}{llll}\text { Part } 8 \text { EIT } & \text { EIT } 641 & \text { Implementation }\end{array}$ of Guidelines in Communities

Part 8 EIT EIT 645 Debriefing of Resuscitation Performance

Part $8 \quad$ EIT $\quad$ EIT $647 \quad$ CPR Instruction Methods (SelfInstruction Versus Traditional)

\section{Among participants undertaking ALS training in an education setting $(P)$, does the use of high-fidelity manikins (I), compared with the use of low-fidelity manikins (C), change patient outcomes, skill performance in actual resuscitations, skill} performance at 1 year, skill performance at time between course conclusion and 1 year, skill performance at course conclusion, cognitive knowledge (0)?

Adults and children in OHCA (P), does transport to a specialist cardiac arrest center (I), compared with no directed transport (C), change neurologically intact survival at 30 days, survival to hospital discharge with good neurologic outcome, survival to hospital discharge, hospital admission, ROSC (0)?

Among students who are taking BLS courses (P), does any specific interval for update or retraining (I), compared with standard practice (ie, 12 or 24 monthly) (C), change patient outcomes, skill performance in actual resuscitations, skill performance at 1 year, skill performance at course conclusion, cognitive knowledge $(0)$ ?

Among students who are taking ALS courses in an educational setting $(P)$, does inclusion of specific leadership or team training (I), compared with no such specific training (C), change patient outcomes, bystander CPR performance, skill performance in actual resuscitations, skill performance at 1 year, skill performance at course conclusion, cognitive knowledge (0)?

Among students who are taking ALS courses in an educational setting (P), does any specific interval for update or retraining (I), compared with standard practice (ie, 12 or 24 monthly) (C), change/improve patient outcomes, skill performance in actual resuscitations, skill performance between course completion and 1 year; skill performance at 1 year, skill performance at course conclusion, cognitive knowledge (0)?

Among students who are taking BLS or ALS courses in a resource-limited educational setting $(\mathrm{P})$, does any educational approach (I), compared with other approaches (C), change clinical outcome, skill performance in actual resuscitations, skill performance at 1 year, skill performance at time between course conclusion and 1 year, skill performance at course conclusion, cognitive knowledge (0)?

Among students who are taking ALS courses in an educational setting (P), does inclusion of specific precourse preparation (eg, eLearning and pretesting) (I), compared with no such preparation (C), change survival rates, skill performance in actual resuscitations, cognitive knowledge, skill performance at course conclusion, skill performance at 1 year, skill performance at time between course conclusion and 1 year $(0)$ ?

Among adults who are at risk for cardiac or respiratory arrest in the hospital $(\mathrm{P})$, does use of the Early Warning Score (EWS)/response teams/MET systems (I), compared with no such responses (C), change survival to hospital discharge, in-hospital incidence of cardiac/respiratory arrest, survival to hospital discharge with good neurologic outcome (0)?

Among resuscitation systems caring for patients in cardiac arrest in any setting $(\mathrm{P})$, does a performance measurement system (I), compared with no system (C), change survival to hospital discharge, skill performance in actual resuscitations, survival to admission, system-level variables $(0)$ ?

Within organizations that provide care for patients in cardiac arrest in any setting (P), does implementation of resuscitation guidelines (I), compared with no such use (C), change survival to 180 days with good neurologic outcome, survival to hospital discharge, bystander CPR performance, ROSC (0)?

Among rescuers who are caring for patients in cardiac arrest in any setting $(\mathrm{P})$, does briefing or debriefing (I), compared with no briefing or debriefing (C), change survival, skill performance in actual resuscitations, improve quality of resuscitation (eg, reduce hands-off time), cognitive knowledge (0)?

Among students who are taking BLS courses in an educational setting $(\mathrm{P})$, does video or computer self-instructions (I), compared with traditional instructorled courses (C), change survival, skill performance in actual resuscitations, skill performance at 1 year, skill performance at course conclusion, cognitive knowledge $(0)$ ?
Evidence Reviewers

Adam Cheng,

Andy Lockey

Judith Finn,

Dion Stub

Taku Iwami,

Theresa

Olasveengen

Koen Monsieurs, Elaine Gilfoyle

Matthew Ma Chih-Wei Yang, Farhan Bhanji

David Kloeck, Traci Wolbrink

Andy Lockey, Mary Mancini, John Bill

Mary Mancini, Robert Frengley

Blair Bigham, Robert Schultz

Jon Rittenberger Theresa

Olasveengen, Patrick Ko

Robert Greif, Dana Edelson

Ming-Ju Hsieh, Matthew Ma, Judy Young 
CoSTR Part 8: PICO Appendix, Continued

\begin{tabular}{|c|c|c|c|c|c|}
\hline Part & Task Force & PICO ID & Short Title & PICO Question & Evidence Reviewers \\
\hline Part 8 & EIT & EIT 648 & $\begin{array}{l}\text { CPR Feedback } \\
\text { Devices in } \\
\text { Training }\end{array}$ & $\begin{array}{l}\text { Among students who are taking BLS or ALS courses in an educational setting } \\
\text { (P), does CPR feedback device use (I), compared with no use of CPR feedback } \\
\text { devices (C), change improve patient outcomes, skill performance in actual } \\
\text { resuscitations, skill performance at } 1 \text { year, skill performance at course } \\
\text { conclusion, cognitive knowledge }(0) \text { ? }\end{array}$ & $\begin{array}{l}\text { Joyce Yeung, } \\
\text { Mary Ann McNeil }\end{array}$ \\
\hline Part 8 & EIT & EIT 649 & $\begin{array}{l}\text { Basic Life Support } \\
\text { Training for High- } \\
\text { Risk Populations }\end{array}$ & $\begin{array}{l}\text { For people at high risk of OHCA (P), does focused training of likely rescuers } \\
\text { (eg, family or caregivers) (I) compared with no such targeting (C), change } \\
\text { survival with favorable neurologic outcome at discharge, ROSC, bystander CPR } \\
\text { performance, number of people trained in CPR, willingness to provide CPR (0)? }\end{array}$ & $\begin{array}{l}\text { Janet Bray, } \\
\text { Marion Leary }\end{array}$ \\
\hline Part 8 & EIT & EIT 651 & $\begin{array}{l}\text { AED Training } \\
\text { Methods }\end{array}$ & $\begin{array}{l}\text { Among students who are taking AED courses in an educational setting }(\mathrm{P}) \text {, does } \\
\text { any specific training intervention }(\mathrm{I}) \text {, compared with traditional lecture/practice } \\
\text { sessions }(\mathrm{C}) \text {, change clinical outcome, skill performance in actual resuscitations, } \\
\text { skill performance at } 1 \text { year, skill performance at course conclusion, cognitive } \\
\text { knowledge, use of AEDs }(0) \text { ? }\end{array}$ & $\begin{array}{c}\text { Jan Breckwoldt, } \\
\text { Henrik Fischer }\end{array}$ \\
\hline Part 8 & EIT & EIT 878 & $\begin{array}{l}\text { Social Media } \\
\text { Technologies }\end{array}$ & $\begin{array}{l}\text { For OHCA (P), does having a citizen CPR responder notified of the event via } \\
\text { technology or social media (I), compared with no such notification }(C) \text {, change } \\
\text { survival to hospital discharge with good neurologic outcome, survival to } \\
\text { hospital discharge, hospital admission, ROSC, bystander CPR rates, time to first } \\
\text { compressions }(0) \text { ? }\end{array}$ & $\begin{array}{l}\text { Zuzana Triska, } \\
\text { Steven Brooks }\end{array}$ \\
\hline Part 8 & EIT & EIT 881 & $\begin{array}{l}\text { Compression-0nly } \\
\text { CPR Training }\end{array}$ & $\begin{array}{l}\text { Among communities that are caring for patients in cardiac arrest in any setting } \\
\text { (P), does teaching compression-only CPR (I), compared with conventional CPR } \\
\text { (C), change survival rates, bystander CPR rates, willingness to provide CPR (0)? }\end{array}$ & $\begin{array}{l}\text { Jonathan Duff, } \\
\text { Aaron Donoghue }\end{array}$ \\
\hline
\end{tabular}

\section{References}

1. Meaney PA, Bobrow BJ, Mancini ME, Christenson J, de Caen AR, Bhanji F, Abella BS, Kleinman ME, Edelson DP, Berg RA, Aufderheide TP, Menon V, Leary M; CPR Quality Summit Investigators, the American Heart Association Emergency Cardiovascular Care Committee, and the Council on Cardiopulmonary, Critical Care, Perioperative and Resuscitation. Cardiopulmonary resuscitation quality: [corrected] improving cardiac resuscitation outcomes both inside and outside the hospital: a consensus statement from the American Heart Association. Circulation. 2013;128:417-435. doi: 10.1161/CIR.0b013e31829d8654.

2. Nichol G, Thomas E, Callaway CW, Hedges J, Powell JL, Aufderheide TP, Rea T, Lowe R, Brown T, Dreyer J, Davis D, Idris A, Stiell I; Resuscitation Outcomes Consortium Investigators. Regional variation in out-of-hospital cardiac arrest incidence and outcome. JAMA. 2008;300:1423-1431. doi: 10.1001/jama.300.12.1423.

3. Perkins GD, Cooke MW. Variability in cardiac arrest survival: the NHS Ambulance Service Quality Indicators. Emerg Med J. 2012;29:3-5. doi: 10.1136/emermed-2011-200758.

4. Søreide E, Morrison L, Hillman K, Monsieurs K, Sunde K, Zideman D, Eisenberg M, Sterz F, Nadkarni VM, Soar J, Nolan JP; Utstein Formula for Survival Collaborators. The formula for survival in resuscitation. Resuscitation. 2013;84:1487-1493. doi: 10.1016/j. resuscitation.2013.07.020.

5. Nolan J, Soar J, Eikeland H. The chain of survival. Resuscitation. 2006;71:270-271. doi: 10.1016/j.resuscitation.2006.09.001.

6. Institute of Medicine. Standards for Systematic Reviews. 2011. http://www. iom.edu/Reports/2011/Finding-What-Works-in-Health-Care-Standardsfor-Systematic-Reviews/Standards.aspx. Accessed May 6, 2015.

7. Schünemann H, Brożek J, Guyatt G, Oxman A. GRADE Handbook. 2013. http://www.guidelinedevelopment.org/handbook/. Accessed May 6, 2015.

8. O'Connor D, Green S, Higgins JPT, eds. Chapter 5: Defining the review questions and developing criteria for including studies. In: The Cochrane Collaboration. Higgins JPT, Green S, eds. Cochrane Handbook for Systematic Reviews of Interventions. Version 5.1.0. 2011. http://handbook. cochrane.org/. Accessed May 6, 2015.

9. Higgins JPT, Altman DG, Sterne J, eds. Chapter 8.5 The Cochrane Collaboration's tool for assessing risk of bias. In: The Cochrane Collaboration. Higgins JPT, Green, S, eds. Cochrane Handbook for Systematic Reviews of Interventions. Version 5.1.0. 2011. http://handbook. cochrane.org/. Accessed May 6, 2015.

10. Whiting PF, Rutjes AW, Westwood ME, Mallett S, Deeks JJ, Reitsma JB, Leeflang MM, Sterne JA, Bossuyt PM; QUADAS-2
Group. QUADAS-2: a revised tool for the quality assessment of diagnostic accuracy studies. Ann Intern Med. 2011;155:529-536. doi: 10.7326/0003-4819-155-8-201110180-00009.

11. Schünemann H, Brożek J, Guyatt G, Oxman A. 5.2.1 Study limitations (risk of bias). In: GRADE Handbook. 2013. http://www.guidelinedevelopment.org/handbook/\#h.m9385o5z3li7. Accessed May 6, 2015.

12. Evidence Prime Inc. GRADEpro Guideline Development Tool. http:// www.guidelinedevelopment.org/. Accessed May 6, 2015.

13. Schünemann H, Brożek J, Guyatt G, Oxman A. 5. Quality of evidence. In: GRADE Handbook. 2013. http://www.guidelinedevelopment.org/ handbook/\#h.9rdbelsnu4iy. Accessed May 6, 2015.

14. Schünemann H, Brożek J, Guyatt G, Oxman A. 5.1 Factors determining the quality of evidence. In: GRADE Handbook. 2013. http://www. guidelinedevelopment.org/handbook/\#h.9rdbelsnu4iy. Accessed May 6,2015 .

15. Kirkpatrick D, Kirkpatrick J. Evaluating Training Programs: The Four Levels. San Francisco, CA: Berrett-Koehler Publishers Inc.;2006.

16. Reder S, Cummings P, Quan L. Comparison of three instructional methods for teaching cardiopulmonary resuscitation and use of an automatic external defibrillator to high school students. Resuscitation. 2006;69:443-453. doi: 10.1016/j.resuscitation.2005.08.020.

17. Bhanji F, Mancini ME, Sinz E, Rodgers DL, McNeil MA, Hoadley TA, Meeks RA, Hamilton MF, Meaney PA, Hunt EA, Nadkarni VM, Hazinski MF. Part 16: education, implementation, and teams: 2010 American Heart Association Guidelines for Cardiopulmonary Resuscitation and Emergency Cardiovascular Care. Circulation. 2010;122(Suppl 3):S920S933. doi: 10.1161/CIRCULATIONAHA.110.971135.

18. Mancini ME, Soar J, Bhanji F, Billi JE, Dennett J, Finn J, Ma MH, Perkins GD, Rodgers DL, Hazinski MF, Jacobs I, Morley PT; Education, Implementation, and Teams Chapter Collaborators. Part 12: education, implementation, and teams: 2010 International Consensus on Cardiopulmonary Resuscitation and Emergency Cardiovascular Care Science With Treatment Recommendations. Circulation. 2010;122(Suppl 2):S539-S581. doi: 10.1161/CIRCULATIONAHA. 110.971143

19. Soar J, Mancini ME, Bhanji F, Billi JE, Dennett J, Finn J, Ma MH, Perkins GD, Rodgers DL, Hazinski MF, Jacobs I, Morley PT; Education, Implementation, and Teams Chapter Collaborators. Part 12: education, implementation, and teams: 2010 International Consensus on Cardiopulmonary Resuscitation and Emergency Cardiovascular Care Science with Treatment Recommendations. Resuscitation. 2010;81 Suppl 1:e288-e330. doi: 10.1016/j.resuscitation.2010.08.030. 
20. Travers AH, Perkins GD, Berg RA, Castren M, Considine J, Escalante R, Gazmuri RJ, Koster RW, Lim SH, Nation KJ, Olasveengen TM, Sakamoto T, Sayre MR, Sierra A, Smyth MA, Stanton D, Vaillancourt C; on behalf of the Basic Life Support Chapter Collaborators. Part 3: adult basic life support and automated external defibrillation: 2015 International Consensus on Cardiopulmonary Resuscitation and Emergency Cardiovascular Care Science With Treatment Recommendations. Circulation. 2015;132(suppl 1):S51-S83. doi: 10.1161/CIR.0000000000000272.

21. Perkins GD, Travers AH, Berg RA, Castren M, Considine J, Escalante R, Gazmuri RJ, Koster RW, Lim SH, Nation KJ, Olasveengen TM, Sakamoto T, Sayre MR, Sierra A, Smyth MA, Stanton D, Vaillancourt C; on behalf of the Basic Life Support Chapter Collaborators. Part 3: adult basic life support and automated external defibrillation: 2015 International Consensus on Cardiopulmonary Resuscitation and Emergency Cardiovascular Care Science With Treatment Recommendations. Resuscitation. 2015. In press.

22. Stiell IG, Brown SP, Christenson J, Cheskes S, Nichol G, Powell J, Bigham B, Morrison LJ, Larsen J, Hess E, Vaillancourt C, Davis DP, Callaway CW; Resuscitation Outcomes Consortium (ROC) Investigators. What is the role of chest compression depth during out-of-hospital cardiac arrest resuscitation? Crit Care Med. 2012;40:1192-1198. doi: 10.1097/ CCM.0b013e31823bc8bb.

23. Abella BS, Sandbo N, Vassilatos P, Alvarado JP, O'Hearn N, Wigder HN, Hoffman P, Tynus K, Vanden Hoek TL, Becker LB. Chest compression rates during cardiopulmonary resuscitation are suboptimal: a prospective study during in-hospital cardiac arrest. Circulation. 2005;111:428-434. doi: 10.1161/01.CIR.0000153811.84257.59.

24. Sutton RM, Wolfe H, Nishisaki A, Leffelman J, Niles D, Meaney PA, Donoghue A, Maltese MR, Berg RA, Nadkarni VM. Pushing harder, pushing faster, minimizing interruptions... but falling short of 2010 cardiopulmonary resuscitation targets during in-hospital pediatric and adolescent resuscitation. Resuscitation. 2013;84:1680-1684. doi: 10.1016/j. resuscitation.2013.07.029.

25. Fabius DB, Grissom EL, Fuentes A. Recertification in cardiopulmonary resuscitation. A comparison of two teaching methods. J Nurs Staff Dev. 1994;10:262-268.

26. Todd KH, Heron SL, Thompson M, Dennis R, O'Connor J, Kellermann AL. Simple CPR: A randomized, controlled trial of video self-instructional cardiopulmonary resuscitation training in an African American church congregation. Ann Emerg Med. 1999;34:730-737.

27. Todd KH, Braslow A, Brennan RT, Lowery DW, Cox RJ, Lipscomb LE, Kellermann AL. Randomized, controlled trial of video self-instruction versus traditional CPR training. Ann Emerg Med. 1998;31:364-369.

28. Nelson M, Brown CG. CPR instruction: modular versus lecture course. Ann Emerg Med. 1984;13:118-121.

29. Chung CH, Siu AY, Po LL, Lam CY, Wong PC. Comparing the effectiveness of video self-instruction versus traditional classroom instruction targeted at cardiopulmonary resuscitation skills for laypersons: a prospective randomised controlled trial. Hong Kong Med J. 2010;16:165-170.

30. Mancini ME, Cazzell M, Kardong-Edgren S, Cason CL. Improving workplace safety training using a self-directed CPR-AED learning program. AAOHN J. 2009;57:159-67; quiz 168.

31. Cason CL, Kardong-Edgren S, Cazzell M, Behan D, Mancini ME. Innovations in basic life support education for healthcare providers: improving competence in cardiopulmonary resuscitation through selfdirected learning. J Nurses Staff Dev. 2009;25:E1-E13. doi: 10.1097/ NND.0b013e3181a56f92.

32. Einspruch EL, Lynch B, Aufderheide TP, Nichol G, Becker L. Retention of CPR skills learned in a traditional AHA Heartsaver course versus 30-min video self-training: a controlled randomized study. Resuscitation. 2007;74:476-486. doi: 10.1016/j.resuscitation.2007.01.030.

33. Dracup K, Moser DK, Doering LV, Guzy PM. Comparison of cardiopulmonary resuscitation training methods for parents of infants at high risk for cardiopulmonary arrest. Ann Emerg Med. 1998;32:170-177.

34. Batcheller AM, Brennan RT, Braslow A, Urrutia A, Kaye W. Cardiopulmonary resuscitation performance of subjects over forty is better following half-hour video self-instruction compared to traditional fourhour classroom training. Resuscitation. 2000;43:101-110.

35. Lynch B, Einspruch EL, Nichol G, Becker LB, Aufderheide TP, Idris A. Effectiveness of a 30-min CPR self-instruction program for lay responders: a controlled randomized study. Resuscitation. 2005;67:31-43. doi: 10.1016/j.resuscitation.2005.04.017.

36. Roppolo LP, Pepe PE, Campbell L, Ohman K, Kulkarni H, Miller R, Idris A, Bean L, Bettes TN, Idris AH. Prospective, randomized trial of the effectiveness and retention of 30-min layperson training for cardiopulmonary resuscitation and automated external defibrillators: The
American Airlines Study. Resuscitation. 2007;74:276-285. doi: 10.1016/j. resuscitation.2006.12.017.

37. Roppolo LP, Heymann R, Pepe P, Wagner J, Commons B, Miller R, Allen E, Horne L, Wainscott MP, Idris AH. A randomized controlled trial comparing traditional training in cardiopulmonary resuscitation (CPR) to self-directed CPR learning in first year medical students: The two-person CPR study. Resuscitation. 2011;82:319-325. doi: 10.1016/j. resuscitation.2010.10.025.

38. Barrington KJ, Finer NN, Etches PC. Succinylcholine and atropine for premedication of the newborn infant before nasotracheal intubation: a randomized, controlled trial. Crit Care Med. 1989;17:1293-1296.

39. de Vries W, Schelvis M, Rustemeijer I, Bierens JJ. Self-training in the use of automated external defibrillators: the same results for less money. Resuscitation. 2008;76:76-82. doi: 10.1016/j.resuscitation. 2007.06.030.

40. de Vries W, Turner NM, Monsieurs KG, Bierens JJ, Koster RW. Comparison of instructor-led automated external defibrillation training and three alternative DVD-based training methods. Resuscitation. 2010;81:1004-1009. doi: 10.1016/j.resuscitation.2010.04.006.

41. Meischke HW, Rea T, Eisenberg MS, Schaeffer SM, Kudenchuk P. Training seniors in the operation of an automated external defibrillator: a randomized trial comparing two training methods. Ann Emerg Med. 2001;38:216-222. doi: 10.1067/mem.2001.115621.

42. Miotto HC, Camargos FR, Ribeiro CV, Goulart EM, Moreira Mda C. Effects of the use of theoretical versus theoretical-practical training on CPR. Arq Bras Cardiol. 2010;95:328-331.

43. Mattei LC, McKay U, Lepper MW, Soar J. Do nurses and physiotherapists require training to use an automated external defibrillator? Resuscitation. 2002;53:277-280.

44. Gundry JW, Comess KA, DeRook FA, Jorgenson D, Bardy GH Comparison of naive sixth-grade children with trained professionals in the use of an automated external defibrillator. Circulation. 1999;100:1703-1707.

45. Beckers SK, Fries M, Bickenbach J, Skorning MH, Derwall M, Kuhlen R, Rossaint R. Retention of skills in medical students following minimal theoretical instructions on semi and fully automated external defibrillators. Resuscitation. 2007;72:444-450. doi: 10.1016/j. resuscitation.2006.08.001.

46. Beckers S, Fries M, Bickenbach J, Derwall M, Kuhlen R, Rossaint R. Minimal instructions improve the performance of laypersons in the use of semiautomatic and automatic external defibrillators. Crit Care. 2005;9:R110-R116. doi: 10.1186/cc3033.

47. Mitchell KB, Gugerty L, Muth E. Effects of brief training on use of automated external defibrillators by people without medical expertise. Hum Factors. 2008;50:301-310.

48. Woollard M, Whitfield R, Newcombe RG, Colquhoun M, Vetter N, Chamberlain D. Optimal refresher training intervals for AED and CPR skills: a randomised controlled trial. Resuscitation. 2006;71:237-247. doi: 10.1016/j.resuscitation.2006.04.005.

49. Frkovic V, Sustic A, Zeidler F, Protic A, Desa K. A brief reeducation in cardiopulmonary resuscitation after six months - the benefit from timely repetition. Signa Vitae. 2008;3:24-28.

50. Oermann MH, Kardong-Edgren SE, Odom-Maryon T. Effects of monthly practice on nursing students' CPR psychomotor skill performance. Resuscitation. 2011;82:447-453. doi: 10.1016/j.resuscitation.2010.11.022.

51. Chamberlain D, Smith A, Woollard M, Colquhoun M, Handley AJ, Leaves S, Kern KB. Trials of teaching methods in basic life support (3): comparison of simulated CPR performance after first training and at 6 months, with a note on the value of re-training. Resuscitation. 2002;53:179-187.

52. Ahn JY, Cho GC, Shon YD, Park SM, Kang KH. Effect of a reminder video using a mobile phone on the retention of CPR and AED skills in lay responders. Resuscitation. 2011;82:1543-1547. doi: 10.1016/j. resuscitation.2011.08.029.

53. Delasobera BE, Goodwin TL, Strehlow M, Gilbert G, D'Souza P, Alok A, Raje P, Mahadevan SV. Evaluating the efficacy of simulators and multimedia for refreshing ACLS skills in India. Resuscitation. 2010;81:217-223. doi: 10.1016/j.resuscitation.2009.10.013.

54. Meaney PA, Sutton RM, Tsima B, Steenhoff AP, Shilkofski N, Boulet JR, Davis A, Kestler AM, Church KK, Niles DE, Irving SY, Mazhani L, Nadkarni VM. Training hospital providers in basic CPR skills in Botswana: acquisition, retention and impact of novel training techniques. Resuscitation. 2012;83:1484-1490. doi: 10.1016/j. resuscitation.2012.04.014. 
55. Jain A, Agarwal R, Chawla D, Paul V, Deorari A. Tele-education vs classroom training of neonatal resuscitation: a randomized trial. J Perinatol. 2010;30:773-779. doi: 10.1038/jp.2010.42.

56. Jenko M, Frangez M, Manohin A. Four-stage teaching technique and chest compression performance of medical students compared to conventional technique. Croat Med J. 2012;53:486-495.

57. Li Q, Ma EL, Liu J, Fang LQ, Xia T. Pre-training evaluation and feedback improve medical students' skills in basic life support. Med Teach. 2011;33:e549-e555. doi: 10.3109/0142159X.2011.600360.

58. Shavit I, Peled S, Steiner IP, Harley DD, Ross S, Tal-Or E, Lemire A. Comparison of outcomes of two skills-teaching methods on lay-rescuers' acquisition of infant basic life support skills. Acad Emerg Med. 2010;17:979-986. doi: 10.1111/j.1553-2712.2010.00849.x.

59. Nilsson C, Sørensen BL, Sørensen JL. Comparing hands-on and video training for postpartum hemorrhage management. Acta Obstet Gynecol Scand. 2014;93:517-520. doi: 10.1111/aogs.12372.

60. Bardy GH, Lee KL, Mark DB, Poole JE, Toff WD, Tonkin AM, Smith W, Dorian P, Packer DL, White RD, Longstreth WT Jr, Anderson J, Johnson G, Bischoff E, Yallop JJ, McNulty S, Ray LD, Clapp-Channing NE, Rosenberg Y, Schron EB; HAT Investigators. Home use of automated external defibrillators for sudden cardiac arrest. $N$ Engl $\mathrm{J} \mathrm{Med}$. 2008;358:1793-1804. doi: 10.1056/NEJMoa0801651.

61. Dracup K, Guzy PM, Taylor SE, Barry J. Cardiopulmonary resuscitation (CPR) training. Consequences for family members of high-risk cardiac patients. Arch Intern Med. 1986;146:1757-1761.

62. Dracup K, Doering LV, Moser DK, Evangelista L. Retention and use of cardiopulmonary resuscitation skills in parents of infants at risk for cardiopulmonary arrest. Pediatr Nurs. 1998;24:219-25; quiz 226.

63. Dracup K, Moser DK, Guzy PM, Taylor SE, Marsden C. Is cardiopulmonary resuscitation training deleterious for family members of cardiac patients? Am J Public Health. 1994;84:116-118.

64. Dracup K, Moser DK, Doering LV, Guzy PM, Juarbe T. A controlled trial of cardiopulmonary resuscitation training for ethnically diverse parents of infants at high risk for cardiopulmonary arrest. Crit Care Med. 2000;28:3289-3295.

65. Eisenberg MS, Moore J, Cummins RO, Andresen E, Litwin PE, Hallstrom AP, Hearne T. Use of the automatic external defibrillator in homes of survivors of out-of-hospital ventricular fibrillation. Am J Cardiol. 1989;63:443-446.

66. Higgins SS, Hardy CE, Higashino SM. Should parents of children with congenital heart disease and life-threatening dysrhythmias be taught cardiopulmonary resuscitation? Pediatrics. 1989;84:1102-1104.

67. McDaniel CM, Berry VA, Haines DE, DiMarco JP. Automatic external defibrillation of patients after myocardial infarction by family members: practical aspects and psychological impact of training. Pacing Clin Electrophysiol. 1988;11(11 Pt 2):2029-2034.

68. McLauchlan CA, Ward A, Murphy NM, Griffith MJ, Skinner DV, Camm AJ. Resuscitation training for cardiac patients and their relatives-its effect on anxiety. Resuscitation. 1992;24:7-11.

69. Pierick TA, Van Waning N, Patel SS, Atkins DL. Self-instructional CPR training for parents of high risk infants. Resuscitation. 2012;83:1140 1144. doi: 10.1016/j.resuscitation.2012.02.007.

70. Sanna T, Fedele F, Genuini I, Puglisi A, Azzolini P, Altamura G, Lobianco F, Ruzzolini M, Perna F, Micò M, Roscio G, Mottironi P, Saraceni C, Pistolese M, Bellocci F. Home defibrillation: a feasibility study in myocardial infarction survivors at intermediate risk of sudden death. Am Heart J. 2006;152:685.e1-685.e7. doi: 10.1016/j.ahj.2006.07.008.

71. Blewer AL, Leary M, Esposito EC, Gonzalez M, Riegel B, Bobrow BJ, Abella BS. Continuous chest compression cardiopulmonary resuscitation training promotes rescuer self-confidence and increased secondary training: a hospital-based randomized controlled trial. Crit Care Med. 2012;40:787-792. doi: 10.1097/CCM.0b013e318236f2ca.

72. Haugk M, Robak O, Sterz F, Uray T, Kliegel A, Losert H, Holzer M, Herkner H, Laggner AN, Domanovits H. High acceptance of a home AED programme by survivors of sudden cardiac arrest and their families. Resuscitation. 2006;70:263-274. doi: 10.1016/j. resuscitation.2006.03.010.

73. Komelasky AL. The effect of home nursing visits on parental anxiety and CPR knowledge retention of parents of apnea-monitored infants. J Pediatr Nurs. 1990;5:387-392.

74. Kliegel A, Scheinecker W, Sterz F, Eisenburger P, Holzer M, Laggner AN. The attitudes of cardiac arrest survivors and their family members towards CPR courses. Resuscitation. 2000;47:147-154.
75. Knight LJ, Wintch S, Nichols A, Arnolde V, Schroeder AR. Saving a life after discharge: CPR training for parents of high-risk children. J Healthc Qual. 2013;35:9-16; quiz17. doi: 10.1111/j.1945-1474.2012.00221.x.

76. Moser DK, Dracup K, Doering LV. Effect of cardiopulmonary resuscitation training for parents of high-risk neonates on perceived anxiety, control, and burden. Heart Lung. 1999;28:326-333. doi: 10.1053/hl.1999. v28.a101053.

77. Schneider L, Sterz F, Haugk M, Eisenburger P, Scheinecker W, Kliegel A, Laggner AN. CPR courses and semi-automatic defibrillators-life saving in cardiac arrest? Resuscitation. 2004;63:295-303. doi: 10.1016/j. resuscitation.2004.06.005.

78. Barr GC Jr, Rupp VA, Hamilton KM, Worrilow CC, Reed JF $3^{\text {rd }}$, Friel KS, Dusza SW, Greenberg MR. Training mothers in infant cardiopulmonary resuscitation with an instructional DVD and manikin. $J$ Am Osteopath Assoc. 2013;113:538-545. doi: 10.7556/jaoa.2013.005.

79. Greenberg MR, Barr GC Jr, Rupp VA, Patel N, Weaver KR, Hamilton $\mathrm{K}$, Reed JF $3^{\text {rd }}$. Cardiopulmonary resuscitation prescription program: a pilot randomized comparator trial. J Emerg Med. 2012;43:166-171. doi: 10.1016/j.jemermed.2011.05.078.

80. Pane GA, Salness KA. Targeted recruitment of senior citizens and cardiac patients to a mass CPR training course. Ann Emerg Med. 1989;18: $152-154$.

81. Brannon TS, White LA, Kilcrease JN, Richard LD, Spillers JG, Phelps CL. Use of instructional video to prepare parents for learning infant cardiopulmonary resuscitation. Proc (Bayl Univ Med Cent). 2009;22:133-137.

82. Dracup K, Heaney DM, Taylor SE, Guzy PM, Breu C. Can family members of high-risk cardiac patients learn cardiopulmonary resuscitation? Arch Intern Med. 1989;149:61-64.

83. Khan JA, Shafquat A, Kundi A. Basic life support skills: assessment and education of spouse and first degree relatives of patients with coronary disease. J Coll Physicians Surg Pak. 2010;20:299-302. doi: 05.2010/ JCPSP.299302.

84. Komelasky AL, Bond BS. The effect of two forms of learning reinforcement upon parental retention of CPR skills. Pediatr Nurs. 1993; 19:96-8, 77

85. Long CA. Teaching parents infant CPR-lecture or audiovisual tape? $M C N$ Am J Matern Child Nurs. 1992;17:30-32.

86. Moore JE, Eisenberg MS, Cummins RO, Hallstrom A, Litwin P, Carter W. Lay person use of automatic external defibrillation. Ann Emerg Med. 1987;16:669-672.

87. Messmer P, Meehan R, Gilliam N, White S, Donaldson P. Teaching infant CPR to mothers of cocaine-positive infants. J Contin Educ Nurs. 1993;24:217-220.

88. Sharieff GQ, Hostetter S, Silva PD. Foster parents of medically fragile children can improve their BLS scores: results of a demonstration project. Pediatr Emerg Care. 2001;17:93-95.

89. Sigsbee M, Geden EA. Effects of anxiety on family members of patients with cardiac disease learning cardiopulmonary resuscitation. Heart Lung. 1990;19:662-665.

90. Wright S, Norton C, Kesten K. Retention of infant CPR instruction by parents. Pediatr Nurs. 1989;15:37-41, 44.

91. Dracup K, Doering LV, Moser DK, Evangelista L. Retention and use of cardiopulmonary resuscitation skills in parents of infants at risk for cardiopulmonary arrest. Pediatr Nurs. 1998;24:219-25; quiz 226.

92. Bobrow BJ, Spaite DW, Berg RA, Stolz U, Sanders AB, Kern KB, Vadeboncoeur TF, Clark LL, Gallagher JV, Stapczynski JS, LoVecchio F, Mullins TJ, Humble WO, Ewy GA. Chest compression-only CPR by lay rescuers and survival from out-of-hospital cardiac arrest. JAMA. 2010;304:1447-1454. doi: 10.1001/jama.2010.1392.

93. Panchal AR, Bobrow BJ, Spaite DW, Berg RA, Stolz U, Vadeboncoeur TF, Sanders AB, Kern KB, Ewy GA. Chest compression-only cardiopulmonary resuscitation performed by lay rescuers for adult out-of-hospital cardiac arrest due to non-cardiac aetiologies. Resuscitation. 2013;84:435439. doi: 10.1016/j.resuscitation.2012.07.038.

94. Cho GC, Sohn YD, Kang KH, Lee WW, Lim KS, Kim W, Oh BJ, Choi $\mathrm{DH}$, Yeom SR, Lim H. The effect of basic life support education on laypersons' willingness in performing bystander hands only cardiopulmonary resuscitation. Resuscitation. 2010;81:691-694. doi: 10.1016/j. resuscitation.2010.02.021.

95. Lam KK, Lau FL, Chan WK, Wong WN. Effect of severe acute respiratory syndrome on bystander willingness to perform cardiopulmonary resuscitation (CPR)-is compression-only preferred to standard CPR? Prehosp Disaster Med. 2007;22:325-329. 
96. Shibata K, Taniguchi T, Yoshida M, Yamamoto K. Obstacles to bystander cardiopulmonary resuscitation in Japan. Resuscitation. 2000;44:187-193.

97. Taniguchi T, Omi W, Inaba H. Attitudes toward the performance of bystander cardiopulmonary resuscitation in Japan. Resuscitation. 2007;75:82-87. doi: 10.1016/j.resuscitation.2007.02.019.

98. Mancini ME, Soar J, Bhanji F, Billi JE, Dennett J, Finn J, Ma MH, Perkins GD, Rodgers DL, Hazinski MF, Jacobs I, Morley PT; Education, Implementation, and Teams Chapter Collaborators. Part 12: education, implementation, and teams: 2010 International Consensus on Cardiopulmonary Resuscitation and Emergency Cardiovascular Care Science With Treatment Recommendations. Circulation. 2010;122(Suppl 2):S539-S581. doi: 10.1161/CIRCULATIONAHA.110.971143.

98a. Perkins GD, Fullerton JN, Davis-Gomez N, Davies RP, Baldock C, Stevens H, Bullock I, Lockey AS. The effect of pre-course e-learning prior to advanced life support training: a randomised controlled trial. Resuscitation. 2010;81:877-881. doi: 10.1016/j. resuscitation.2010.03.019.

99. Lo BM, Devine AS, Evans DP, Byars DV, Lamm OY, Lee RJ, Lowe SM, Walker LL. Comparison of traditional versus high-fidelity simulation in the retention of ACLS knowledge. Resuscitation. 2011;82:1440-1443. doi: 10.1016/j.resuscitation.2011.06.017.

100. Settles J, Jeffries PR, Smith TM, Meyers JS. Advanced cardiac life support instruction: do we know tomorrow what we know today? J Contin Educ Nurs. 2011;42:271-279. doi: 10.3928/00220124-20110315-01.

101. Cheng Y, Xue FS, Cui XL. Removal of a laryngeal foreign body under videolaryngoscopy. Resuscitation. 2013;84:e1-e2. doi: 10.1016/j. resuscitation.2012.09.038.

102. Cherry RA, Williams J, George J, Ali J. The effectiveness of a human patient simulator in the ATLS shock skills station. J Surg Res. 2007;139:229-235. doi: 10.1016/j.jss.2006.08.010.

103. Conlon LW, Rodgers DL, Shofer FS, Lipschik GY. Impact of levels of simulation fidelity on training of interns in ACLS. Hosp Pract (1995). 2014;42:135-141. doi: 10.3810/hp.2014.10.1150.

104. Coolen EH, Draaisma JM, Hogeveen M, Antonius TA, Lommen CM, Loeffen JL. Effectiveness of high fidelity video-assisted real-time simulation: a comparison of three training methods for acute pediatric emergencies. Int J Pediatr. 2012;2012:709569. doi: 10.1155/2012/709569.

105. Curran V, Fleet L, White S, Bessell C, Deshpandey A, Drover A, Hayward M, Valcour J. A randomized controlled study of manikin simulator fidelity on neonatal resuscitation program learning outcomes. Adv Health Sci Educ Theory Pract. 2015;20:205-218. doi: 10.1007/ s10459-014-9522-8.

106. Donoghue AJ, Durbin DR, Nadel FM, Stryjewski GR, Kost SI, Nadkarni VM. Effect of high-fidelity simulation on Pediatric Advanced Life Support training in pediatric house staff: a randomized trial. Pediatr Emerg Care. 2009;25:139-144. doi: 10.1097/ PEC.0b013e31819a7f90.

107. Finan E, Bismilla Z, Whyte HE, Leblanc V, McNamara PJ. High-fidelity simulator technology may not be superior to traditional low-fidelity equipment for neonatal resuscitation training. J Perinatol. 2012;32: 287-292. doi: 10.1038/jp.2011.96.

108. Hoadley TA. Learning advanced cardiac life support: a comparison study of the effects of low- and high-fidelity simulation. Nurs Educ Perspect. 2009;30:91-95.

109. Owen H, Mugford B, Follows V, Plummer JL. Comparison of three simulation-based training methods for management of medical emergencies. Resuscitation. 2006;71:204-211. doi: 10.1016/j. resuscitation.2006.04.007.

110. Thomas EJ, Williams AL, Reichman EF, Lasky RE, Crandell S, Taggart WR. Team training in the neonatal resuscitation program for interns: teamwork and quality of resuscitations. Pediatrics. 2010;125:539-546. doi: 10.1542/peds.2009-1635.

111. Rodgers DL, Securro S Jr, Pauley RD. The effect of high-fidelity simulation on educational outcomes in an advanced cardiovascular life support course. Simul Healthc. 2009;4:200-206. doi: 10.1097/ SIH.0b013e3181b1b877.

112. Campbell DM, Barozzino T, Farrugia M, Sgro M. High-fidelity simulation in neonatal resuscitation. Paediatr Child Health. 2009;14:19-23.

113. King JM, Reising DL. Teaching advanced cardiac life support protocols: the effectiveness of static versus high-fidelity simulation. Nurse Educ. 2011;36:62-65. doi: 10.1097/NNE.0b013e31820b5012.

114. Cheng A, Lang TR, Starr SR, Pusic M, Cook DA. Technology-enhanced simulation and pediatric education: a meta-analysis. Pediatrics. 2014;133:e1313-e1323. doi: 10.1542/peds.2013-2139.
115. Andreatta P, Saxton E, Thompson M, Annich G. Simulation-based mock codes significantly correlate with improved pediatric patient cardiopulmonary arrest survival rates. Pediatr Crit Care Med. 2011;12:33-38. doi: 10.1097/PCC.0b013e3181e89270.

116. Neily J, Mills PD, Young-Xu Y, Carney BT, West P, Berger DH, Mazzia LM, Paull DE, Bagian JP. Association between implementation of a medical team training program and surgical mortality. JAMA. 2010;304:1693-1700. doi: 10.1001/jama.2010.1506.

117. Weidman EK, Bell G, Walsh D, Small S, Edelson DP. Assessing the impact of immersive simulation on clinical performance during actual in-hospital cardiac arrest with CPR-sensing technology: A randomized feasibility study. Resuscitation. 2010;81:1556-1561. doi: 10.1016/j. resuscitation.2010.05.021.

118. Nadler I, Sanderson PM, Van Dyken CR, Davis PG, Liley HG. Presenting video recordings of newborn resuscitations in debriefings for teamwork training. BMJ Qual Saf. 2011;20:163-169. doi: 10.1136/ bmjqs.2010.043547.

119. Su L, Spaeder MC, Jones MB, Sinha P, Nath DS, Jain PN, Berger JT, Williams L, Shankar V. Implementation of an extracorporeal cardiopulmonary resuscitation simulation program reduces extracorporeal cardiopulmonary resuscitation times in real patients. Pediatr Crit Care Med. 2014;15:856-860. doi: 10.1097/PCC.0000000000000234.

120. Hunziker S, Bühlmann C, Tschan F, Balestra G, Legeret C, Schumacher C, Semmer NK, Hunziker P, Marsch S. Brief leadership instructions improve cardiopulmonary resuscitation in a high-fidelity simulation: a randomized controlled trial. Crit Care Med. 2010;38:1086-1091. doi: 10.1097/CCM.0b013e3181cf7383.

121. Garbee DD, Paige J, Barrier K, Kozmenko V, Kozmenko L, Zamjahn J, Bonanno L, Cefalu J. Interprofessional teamwork among students in simulated codes: a quasi-experimental study. Nurs Educ Perspect. 2013;34:339-344.

122. Gilfoyle E, Gottesman R, Razack S. Development of a leadership skills workshop in paediatric advanced resuscitation. Med Teach. 2007;29:e276-e283. doi: 10.1080/01421590701663287.

123. Chung SP, Cho J, Park YS, Kang HG, Kim CW, Song KJ, Lim H, Cho GC. Effects of script-based role play in cardiopulmonary resuscitation team training. Emerg Med J. 2011;28:690-694. doi: 10.1136/ emj.2009.090605.

124. Fernandez Castelao E, Russo SG, Cremer S, Strack M, Kaminski L, Eich C, Timmermann A, Boos M. Positive impact of crisis resource management training on no-flow time and team member verbalisations during simulated cardiopulmonary resuscitation: a randomised controlled trial. Resuscitation. 2011;82:1338-1343. doi: 10.1016/j.resuscitation.2011.05.009.

125. Fernandez R, Pearce M, Grand JA, Rench TA, Jones KA, Chao GT, Kozlowski SW. Evaluation of a computer-based educational intervention to improve medical teamwork and performance during simulated patient resuscitations. Crit Care Med. 2013;41:2551-2562. doi: 10.1097/ CCM.0b013e31829828f7.

126. Hunziker S, Tschan F, Semmer NK, Zobrist R, Spychiger M, Breuer M, Hunziker PR, Marsch SC. Hands-on time during cardiopulmonary resuscitation is affected by the process of teambuilding: a prospective randomised simulator-based trial. BMC Emerg Med. 2009;9:3. doi: 10.1186/1471-227X-9-3.

127. Jankouskas TS, Haidet KK, Hupcey JE, Kolanowski A, Murray WB. Targeted crisis resource management training improves performance among randomized nursing and medical students. Simul Healthc. 2011;6:316-326. doi: 10.1097/SIH.0b013e31822bc676.

128. Blackwood J, Duff JP, Nettel-Aguirre A, Djogovic D, Joynt C. Does teaching crisis resource management skills improve resuscitation performance in pediatric residents?. Pediatr Crit Care Med. 2014;15: e168-e174. doi: 10.1097/PCC.0000000000000100.

129. DeVita MA, Schaefer J, Lutz J, Wang H, Dongilli T. Improving medical emergency team (MET) performance using a novel curriculum and a computerized human patient simulator. Qual Saf Health Care. 2005;14:326-331. doi: 10.1136/qshc.2004.011148.

130. Mäkinen M, Aune S, Niemi-Murola L, Herlitz J, Varpula T, Nurmi J, Axelsson AB, Thorén AB, Castrén M; ECCE Study Group. Assessment of CPR-D skills of nurses in Göteborg, Sweden and Espoo, Finland: teaching leadership makes a difference. Resuscitation. 2007;72: 264-269. doi: 10.1016/j.resuscitation.2006.06.032.

131. Yeung JH, Ong GJ, Davies RP, Gao F, Perkins GD. Factors affecting team leadership skills and their relationship with quality of cardiopulmonary resuscitation. Crit Care Med. 2012;40:2617-2621. doi: 10.1097/ CCM.0b013e3182591fda. 
132. Thomas EJ, Taggart B, Crandell S, Lasky RE, Williams AL, Love LJ, Sexton JB, Tyson JE, Helmreich RL. Teaching teamwork during the Neonatal Resuscitation Program: a randomized trial. $J$ Perinatol. 2007;27:409-414. doi: 10.1038/sj.jp.7211771.

133. Sawyer T, Leonard D, Sierocka-Castaneda A, Chan D, Thompson M. Correlations between technical skills and behavioral skills in simulated neonatal resuscitations. J Perinatol. 2014;34:781-786. doi: 10.1038/ jp.2014.93.

134. Cooper S. Developing leaders for advanced life support: evaluation of a training programme. Resuscitation. 2001;49:33-38.

135. Stross JK. Maintaining competency in advanced cardiac life support skills. JAMA. 1983;249:3339-3341.

136. Jensen ML, Mondrup F, Lippert F, Ringsted C. Using e-learning for maintenance of ALS competence. Resuscitation. 2009;80:903-908. doi: 10.1016/j.resuscitation.2009.06.005.

137. Kurosawa H, Ikeyama T, Achuff P, Perkel M, Watson C, Monachino A, Remy D, Deutsch E, Buchanan N, Anderson J, Berg RA, Nadkarni VM, Nishisaki A. A randomized, controlled trial of in situ pediatric advanced life support recertification ("pediatric advanced life support reconstructed") compared with standard pediatric advanced life support recertification for ICU frontline providers. Crit Care Med. 2014;42:610-618. doi: 10.1097/CCM.0000000000000024.

138. Bender J, Kennally K, Shields R, Overly F. Does simulation booster impact retention of resuscitation procedural skills and teamwork? J Perinatol. 2014;34:664-668. doi: 10.1038/jp.2014.72.

139. Kaczorowski J, Levitt C, Hammond M, Outerbridge E, Grad R, Rothman A, Graves L. Retention of neonatal resuscitation skills and knowledge: a randomized controlled trial. Fam Med. 1998;30:705-711.

139a. Su E, Schmidt TA, Mann NC, Zechnich AD. A randomized controlled trial to assess decay in acquired knowledge among paramedics completing a pediatric resuscitation course. Acad Emerg Med. 2000;7:779-786.

140. Patocka C, Khan F, Dubrovsky AS, Brody D, Bank I, Bhanji F. Pediatric resuscitation training-instruction all at once or spaced over time? Resuscitation. 2015;88:6-11. doi: 10.1016/j.resuscitation.2014.12.003.

141. Bigham BL, Koprowicz K, Rea T, Dorian P, Aufderheide TP, Davis DP, Powell J, Morrison LJ; ROC Investigators. Cardiac arrest survival did not increase in the Resuscitation Outcomes Consortium after implementation of the 2005 AHA CPR and ECC guidelines. Resuscitation. 2011;82:979-983. doi: 10.1016/j.resuscitation.2011.03.024.

142. Olasveengen TM, Vik E, Kuzovlev A, Sunde K. Effect of implementation of new resuscitation guidelines on quality of cardiopulmonary resuscitation and survival. Resuscitation. 2009;80:407-411. doi: 10.1016/j. resuscitation.2008.12.005.

143. Bigham BL, Aufderheide TP, Davis DP, Powell J, Donn S, Suffoletto B, Nafziger S, Stouffer J, Morrison LJ; ROC Investigators. Knowledge translation in emergency medical services: a qualitative survey of barriers to guideline implementation. Resuscitation. 2010;81:836-840. doi: 10.1016/j.resuscitation.2010.03.012.

144. Aufderheide TP, Yannopoulos D, Lick CJ, Myers B, Romig LA, Stothert JC, Barnard J, Vartanian L, Pilgrim AJ, Benditt DG. Implementing the 2005 American Heart Association Guidelines improves outcomes after out-of-hospital cardiac arrest. Heart Rhythm. 2010;7:1357-1362. doi: 10.1016/j.hrthm.2010.04.022.

145. Rea TD, Helbock M, Perry S, Garcia M, Cloyd D, Becker L, Eisenberg M. Increasing use of cardiopulmonary resuscitation during outof-hospital ventricular fibrillation arrest: survival implications of guideline changes. Circulation. 2006;114:2760-2765. doi: 10.1161/ CIRCULATIONAHA.106.654715.

146. Steinmetz J, Barnung S, Nielsen SL, Risom M, Rasmussen LS. Improved survival after an out-of-hospital cardiac arrest using new guidelines. Acta Anaesthesiol Scand. 2008;52:908-913. doi: 10.1111/j.1399-6576.2008.01657.x.

147. Garza AG, Gratton MC, Salomone JA, Lindholm D, McElroy J, Archer R. Improved patient survival using a modified resuscitation protocol for out-of-hospital cardiac arrest. Circulation. 2009;119:2597-2605. doi: 10.1161/CIRCULATIONAHA.108.815621.

148. Deasy C, Bray JE, Smith K, Wolfe R, Harriss LR, Bernard SA, Cameron P. Cardiac arrest outcomes before and after the 2005 resuscitation guidelines implementation: evidence of improvement? Resuscitation. 2011;82:984-988. doi: 10.1016/j.resuscitation.2011.04.005.

149. Kudenchuk PJ, Redshaw JD, Stubbs BA, Fahrenbruch CE, Dumas F, Phelps R, Blackwood J, Rea TD, Eisenberg MS. Impact of changes in resuscitation practice on survival and neurological outcome after out-of-hospital cardiac arrest resulting from nonshockable arrhythmias. Circulation. 2012;125:1787-1794. doi: 10.1161/ CIRCULATIONAHA.111.064873.

150. Sayre MR, Cantrell SA, White LJ, Hiestand BC, Keseg DP, Koser S. Impact of the 2005 American Heart Association cardiopulmonary resuscitation and emergency cardiovascular care guidelines on out-ofhospital cardiac arrest survival. Prehosp Emerg Care. 2009;13:469-477. doi: 10.1080/10903120903144965.

151. Hung SW, Chen CC, Shih HC, Huang CF, Chen KC, Chong CF, Wang TL. Are new resuscitation guidelines better? Experience of an Asian metropolitan hospital. Ann Acad Med Singapore. 2010;39:569-567.

152. Robinson S, Swain AH, Hoyle SR, Larsen PD. Survival from out-ofhospital cardiac arrest in New Zealand following the 2005 resuscitation guideline changes. Resuscitation. 2010;81:1648-1651. doi: 10.1016/j. resuscitation.2010.07.009.

153. Andrews JC, Schünemann HJ, Oxman AD, Pottie K, Meerpohl JJ, Coello PA, Rind D, Montori VM, Brito JP, Norris S, Elbarbary M, Post P, Nasser M, Shukla V, Jaeschke R, Brozek J, Djulbegovic B, Guyatt G. GRADE guidelines: 15 . Going from evidence to recommendation-determinants of a recommendation's direction and strength. J Clin Epidemiol. 2013;66:726-735. doi: 10.1016/j.jclinepi.2013.02.003.

154. Kajino K, Iwami T, Daya M, Nishiuchi T, Hayashi Y, Kitamura T, Irisawa T, Sakai T, Kuwagata Y, Hiraide A, Kishi M, Yamayoshi S. Impact of transport to critical care medical centers on outcomes after out-of-hospital cardiac arrest. Resuscitation. 2010;81:549-554. doi: 10.1016/j.resuscitation.2010.02.008.

155. Callaway CW, Schmicker R, Kampmeyer M, Powell J, Rea TD, Daya MR, Aufderheide TP, Davis DP, Rittenberger JC, Idris AH, Nichol G; Resuscitation Outcomes Consortium (ROC) Investigators. Receiving hospital characteristics associated with survival after out-of-hospital cardiac arrest. Resuscitation. 2010;81:524-529. doi: 10.1016/j. resuscitation.2009.12.006.

156. Callaway CW, Schmicker RH, Brown SP, Albrich JM, Andrusiek DL, Aufderheide TP, Christenson J, Daya MR, Falconer D, Husa RD, Idris AH, Ornato JP, Rac VE, Rea TD, Rittenberger JC, Sears G, Stiell IG; ROC Investigators. Early coronary angiography and induced hypothermia are associated with survival and functional recovery after out-ofhospital cardiac arrest. Resuscitation. 2014;85:657-663. doi: 10.1016/j. resuscitation.2013.12.028.

157. Carr BG, Kahn JM, Merchant RM, Kramer AA, Neumar RW. Interhospital variability in post-cardiac arrest mortality. Resuscitation. 2009;80:30-34. doi: 10.1016/j.resuscitation.2008.09.001.

158. Cudnik MT, Sasson C, Rea TD, Sayre MR, Zhang J, Bobrow BJ, Spaite DW, McNally B, Denninghoff K, Stolz U. Increasing hospital volume is not associated with improved survival in out of hospital cardiac arrest of cardiac etiology. Resuscitation. 2012;83:862-868. doi: 10.1016/j. resuscitation.2012.02.006.

159. Engdahl J, Abrahamsson P, Bång A, Lindqvist J, Karlsson T, Herlitz J. Is hospital care of major importance for outcome after out-of-hospital cardiac arrest? Experience acquired from patients with out-of-hospital cardiac arrest resuscitated by the same Emergency Medical Service and admitted to one of two hospitals over a 16-year period in the municipality of Göteborg. Resuscitation. 2000;43:201-211.

160. Hansen M, Fleischman R, Meckler G, Newgard CD. The association between hospital type and mortality among critically ill children in US EDs. Resuscitation. 2013;84:488-491. doi: 10.1016/j. resuscitation.2012.07.032.

161. Herlitz J, Engdahl J, Svensson L, Angquist KA, Silfverstolpe J, Holmberg S. Major differences in 1-month survival between hospitals in Sweden among initial survivors of out-of-hospital cardiac arrest. Resuscitation. 2006;70:404-409. doi: 10.1016/j.resuscitation.2006.01.014.

162. Kjaergaard J, Bro-Jeppesen J, Rasmussen LS, Nielsen SL, Folke F, Lippert F, Wanscher MC, Hassager C. [Differences between hospitals in prognosis after resuscitated out-of-hospital cardiac arrest patients]. Ugeskr Laeger. 2009;171:2169-2173.

163. Lee SJ, Jeung KW, Lee BK, Min YI, Park KN, Suh GJ, Kim KS, Kang $\mathrm{GH}$; Korean Hypothermia Network (KorHN) Investigators. Impact of case volume on outcome and performance of targeted temperature management in out-of-hospital cardiac arrest survivors. Am J Emerg Med. 2015;33:31-36. doi: 10.1016/j.ajem.2014.10.003.

164. Stub D, Smith K, Bray JE, Bernard S, Duffy SJ, Kaye DM. Hospital characteristics are associated with patient outcomes following outof-hospital cardiac arrest. Heart. 2011;97:1489-1494. doi: 10.1136/ hrt.2011.226431.

165. Bosson N, Kaji AH, Niemann JT, Eckstein M, Rashi P, Tadeo R, Gorospe D, Sung G, French WJ, Shavelle D, Thomas JL, Koenig W. 
Survival and neurologic outcome after out-of-hospital cardiac arrest: results one year after regionalization of post-cardiac arrest care in a large metropolitan area. Prehosp Emerg Care. 2014;18:217-223. doi: 10.3109/10903127.2013.856507.

166. Fothergill RT, Watson LR, Virdi GK, Moore FP, Whitbread M. Survival of resuscitated cardiac arrest patients with ST-elevation myocardial infarction (STEMI) conveyed directly to a Heart Attack Centre by ambulance clinicians. Resuscitation. 2014;85:96-98. doi: 10.1016/j. resuscitation.2013.09.010.

167. Lick CJ, Aufderheide TP, Niskanen RA, Steinkamp JE, Davis SP, Nygaard SD, Bemenderfer KK, Gonzales L, Kalla JA, Wald SK, Gillquist DL, Sayre MR, Osaki Holm SY, Oski Holm SY, Oakes DA, Provo TA, Racht EM, Olsen JD, Yannopoulos D, Lurie KG. Take Heart America: A comprehensive, community-wide, systems-based approach to the treatment of cardiac arrest. Crit Care Med. 2011;39:26-33. doi: 10.1097/CCM.0b013e3181fa7ce4.

168. Lund-Kordahl I, Olasveengen TM, Lorem T, Samdal M, Wik L, Sunde K. Improving outcome after out-of-hospital cardiac arrest by strengthening weak links of the local Chain of Survival; quality of advanced life support and post-resuscitation care. Resuscitation. 2010;81:422-426. doi: 10.1016/j.resuscitation.2009.12.020.

169. Spaite DW, Bobrow BJ, Stolz U, Berg RA, Sanders AB, Kern KB, Chikani V, Humble W, Mullins T, Stapczynski JS, Ewy GA; Arizona Cardiac Receiving Center Consortium. Statewide regionalization of postarrest care for out-of-hospital cardiac arrest: association with survival and neurologic outcome. Ann Emerg Med. 2014;64:496-506.e1. doi: 10.1016/j.annemergmed.2014.05.028.

170. Tagami T, Hirata K, Takeshige T, Matsui J, Takinami M, Satake M, Satake S, Yui T, Itabashi K, Sakata T, Tosa R, Kushimoto S, Yokota H, Hirama H. Implementation of the fifth link of the chain of survival concept for out-of-hospital cardiac arrest. Circulation. 2012;126:589-597. doi: 10.1161/CIRCULATIONAHA.111.086173.

171. Davis DP, Fisher R, Aguilar S, Metz M, Ochs G, McCallum-Brown L, Ramanujam P, Buono C, Vilke GM, Chan TC, Dunford JV. The feasibility of a regional cardiac arrest receiving system. Resuscitation. 2007;74:44-51. doi: 10.1016/j.resuscitation.2006.11.009.

172. Heffner AC, Pearson DA, Nussbaum ML, Jones AE. Regionalization of post-cardiac arrest care: implementation of a cardiac resuscitation center. Am Heart J. 2012;164:493-501.e2. doi: 10.1016/j.ahj.2012.06.014.

173. Kang MJ, Lee TR, Shin TG, Sim MS, Jo IJ, Song KJ, Jeong YK. Survival and neurologic outcomes of out-of-hospital cardiac arrest patients who were transferred after return of spontaneous circulation for integrated post-cardiac arrest syndrome care: the another feasibility of the cardiac arrest center. J Korean Med Sci. 2014;29:1301-1307. doi: 10.3346/ jkms.2014.29.9.1301

174. Mooney MR, Unger BT, Boland LL, Burke MN, Kebed KY, Graham KJ, Henry TD, Katsiyiannis WT, Satterlee PA, Sendelbach S, Hodges JS, Parham WM. Therapeutic hypothermia after out-ofhospital cardiac arrest: evaluation of a regional system to increase access to cooling. Circulation. 2011;124:206-214. doi: 10.1161/ CIRCULATIONAHA.110.986257.

175. Spaite DW, Bobrow BJ, Vadeboncoeur TF, Chikani V, Clark L, Mullins T, Sanders AB. The impact of prehospital transport interval on survival in out-of-hospital cardiac arrest: implications for regionalization of post-resuscitation care. Resuscitation. 2008;79:61-66. doi: 10.1016/j. resuscitation.2008.05.006.

176. Spaite DW, Stiell IG, Bobrow BJ, de Boer M, Maloney J, Denninghoff K, Vadeboncoeur TF, Dreyer J, Wells GA. Effect of transport interval on out-of-hospital cardiac arrest survival in the OPALS study: implications for triaging patients to specialized cardiac arrest centers. Ann Emerg Med. 2009;54:248-255. doi: 10.1016/j.annemergmed.2008.11.020.

177. Hartke A, Mumma BE, Rittenberger JC, Callaway CW, Guyette FX. Incidence of re-arrest and critical events during prolonged transport of post-cardiac arrest patients. Resuscitation. 2010;81:938-942. doi: 10.1016/j.resuscitation.2010.04.012.

178. Martin-Gill C, Dilger CP, Guyette FX, Rittenberger JC, Callaway CW. Regional impact of cardiac arrest center criteria on out-of-hospital transportation practices. Prehosp Emerg Care. 2011;15:381-387. doi: 10.3109/10903127.2011.561409.

178a. Carr BG, Goyal M, Band RA, Gaieski DF, Abella BS, Merchant RM, Branas CC, Becker LB, Neumar RW. A national analysis of the relationship between hospital factors and post-cardiac arrest mortality. Intensive Care Med. 2009;35:505-11. doi: 10.1007/s00134-008-1335-x.

178b. Ringh M, Rosenqvist M, Hollenberg J, Jonsson M, Fredman D, Nordberg P, Järnbert-Pettersson H, Hasselqvist-Ax I, Riva G, Svensson
L. Mobile-phone dispatch of laypersons for CPR in out-of-hospital cardiac arrest. $N$ Engl J Med. 2015;372:2316-2325. doi: 10.1056/ NEJMoa1406038.

179. Zijlstra JA, Stieglis R, Riedijk F, Smeekes M, van der Worp WE, Koster RW. Local lay rescuers with AEDs, alerted by text messages, contribute to early defibrillation in a Dutch out-of-hospital cardiac arrest dispatch system. Resuscitation. 2014;85:1444-1449. doi: 10.1016/j. resuscitation.2014.07.020.

180. Ringh M, Fredman D, Nordberg P, Stark T, Hollenberg J. Mobile phone technology identifies and recruits trained citizens to perform CPR on out-of-hospital cardiac arrest victims prior to ambulance arrival. Resuscitation. 2011;82:1514-1518. doi: 10.1016/j. resuscitation.2011.07.033.

181. Stiell IG, Wells GA, Field BJ, Spaite DW, De Maio VJ, Ward R, Munkley DP, Lyver MB, Luinstra LG, Campeau T, Maloney J, Dagnone E. Improved out-of-hospital cardiac arrest survival through the inexpensive optimization of an existing defibrillation program: OPALS study phase II. Ontario Prehospital Advanced Life Support. JAMA. 1999;281:1175-1181.

182. Olasveengen TM, Tomlinson AE, Wik L, Sunde K, Steen PA, Myklebust H, Kramer-Johansen J. A failed attempt to improve quality of out-ofhospital CPR through performance evaluation. Prehosp Emerg Care. 2007;11:427-433. doi: 10.1080/10903120701536628.

183. Clarke S, Lyon R, Milligan D, Clegg G. Resuscitation feedback and targeted education improves quality of pre-hospital resuscitation in Scotland. Eur Heart J. 2011;28:(suppl 1):-A6.

184. Fletcher D, Galloway R, Chamberlain D, Pateman J, Bryant G, Newcombe RG. Basics in advanced life support: a role for download audit and metronomes. Resuscitation. 2008;78:127-134. doi: 10.1016/j. resuscitation.2008.03.003.

185. Edelson DP, Litzinger B, Arora V, Walsh D, Kim S, Lauderdale DS, Vanden Hoek TL, Becker LB, Abella BS. Improving in-hospital cardiac arrest process and outcomes with performance debriefing. Arch Intern Med. 2008;168:1063-1069. doi: 10.1001/archinte.168.10.1063.

186. Wolfe H, Zebuhr C, Topjian AA, Nishisaki A, Niles DE, Meaney PA, Boyle L, Giordano RT, Davis D, Priestley M, Apkon M, Berg RA, Nadkarni VM, Sutton RM. Interdisciplinary ICU cardiac arrest debriefing improves survival outcomes. Crit Care Med. 2014;42:1688-1695. doi: 10.1097/CCM.0000000000000327.

187. Bradley SM, Huszti E, Warren SA, Merchant RM, Sayre MR, Nichol G. Duration of hospital participation in Get With The GuidelinesResuscitation and survival of in-hospital cardiac arrest. Resuscitation. 2012;83:1349-1357. doi: 10.1016/j.resuscitation.2012.03.014.

188. Rittenberger JC, Guyette FX, Tisherman SA, DeVita MA, Alvarez RJ, Callaway CW. Outcomes of a hospital-wide plan to improve care of comatose survivors of cardiac arrest. Resuscitation. 2008;79:198-204. doi: 10.1016/j.resuscitation.2008.08.014.

189. Jiang C, Zhao Y, Chen Z, Chen S, Yang X. Improving cardiopulmonary resuscitation in the emergency department by real-time video recording and regular feedback learning. Resuscitation. 2010;81:1664-1669. doi: 10.1016/j.resuscitation.2010.06.023.

190. Deleted in proof.

191. Spooner BB, Fallaha JF, Kocierz L, Smith CM, Smith SC, Perkins GD. An evaluation of objective feedback in basic life support (BLS) training. Resuscitation. 2007;73:417-424. doi: 10.1016/j. resuscitation.2006.10.017.

192. Mpotos N, Lemoyne S, Calle PA, Deschepper E, Valcke M, Monsieurs KG. Combining video instruction followed by voice feedback in a self-learning station for acquisition of Basic Life Support skills: a randomised non-inferiority trial. Resuscitation. 2011;82:896-901. doi: 10.1016/j.resuscitation.2011.02.024.

193. Cheng A, Brown LL, Duff JP, Davidson J, Overly F, Tofil NM, Peterson DT, White ML, Bhanji F, Bank I, Gottesman R, Adler M, Zhong J, Grant V, Grant DJ, Sudikoff SN, Marohn K, Charnovich A, Hunt EA, Kessler DO, Wong H, Robertson N, Lin Y, Doan Q, Duval-Arnould JM, Nadkarni VM; International Network for Simulation-Based Pediatric Innovation, Research, \& Education (INSPIRE) CPR Investigators. Improving cardiopulmonary resuscitation with a CPR feedback device and refresher simulations (CPR CARES Study): a randomized clinical trial. JAMA Pediatr. 2015;169:137-144. doi: 10.1001/ jamapediatrics.2014.2616.

194. Yeung J, Davies R, Gao F, Perkins GD. A randomised control trial of prompt and feedback devices and their impact on quality of chest compressions-a simulation study. Resuscitation. 2014;85:553-559. doi: 10.1016/j.resuscitation.2014.01.015. 
195. Fischer H, Gruber J, Neuhold S, Frantal S, Hochbrugger E, Herkner H, Schöchl H, Steinlechner B, Greif R. Effects and limitations of an AED with audiovisual feedback for cardiopulmonary resuscitation: a randomized manikin study. Resuscitation. 2011;82:902-907. doi: 10.1016/j. resuscitation.2011.02.023.

196. Noordergraaf GJ, Drinkwaard BW, van Berkom PF, van Hemert HP, Venema A, Scheffer GJ, Noordergraaf A. The quality of chest compressions by trained personnel: the effect of feedback, via the CPREzy, in a randomized controlled trial using a manikin model. Resuscitation. 2006;69:241-252. doi: 10.1016/j.resuscitation.2005.08.008.

197. Sutton RM, Niles D, Meaney PA, Aplenc R, French B, Abella BS, Lengetti EL, Berg RA, Helfaer MA, Nadkarni V. "Booster" training: evaluation of instructor-led bedside cardiopulmonary resuscitation skill training and automated corrective feedback to improve cardiopulmonary resuscitation compliance of Pediatric Basic Life Support providers during simulated cardiac arrest. Pediatr Crit Care Med. 2011;12:e116e121. doi: 10.1097/PCC.0b013e3181e91271.

198. Wik L, Thowsen J, Steen PA. An automated voice advisory manikin system for training in basic life support without an instructor. A novel approach to CPR training. Resuscitation. 2001;50:167-172.

199. Beckers SK, Skorning MH, Fries M, Bickenbach J, Beuerlein S, Derwall M, Kuhlen R, Rossaint R. CPREzy improves performance of external chest compressions in simulated cardiac arrest. Resuscitation. 2007;72:100-107. doi: 10.1016/j.resuscitation.2006.05.020.

200. Perkins GD, Augré C, Rogers H, Allan M, Thickett DR. CPREzy: an evaluation during simulated cardiac arrest on a hospital bed. Resuscitation. 2005;64:103-108. doi: 10.1016/j.resuscitation.2004.08.011.

201. Skorning M, Derwall M, Brokmann JC, Rörtgen D, Bergrath S, Pflipsen J, Beuerlein S, Rossaint R, Beckers SK. External chest compressions using a mechanical feedback device: cross-over simulation study. Anaesthesist. 2011;60:717-722. doi: 10.1007/s00101-011-1871-6.

202. Dine CJ, Gersh RE, Leary M, Riegel BJ, Bellini LM, Abella BS. Improving cardiopulmonary resuscitation quality and resuscitation training by combining audiovisual feedback and debriefing. Crit Care Med. 2008;36:2817-2822. doi: 10.1097/CCM.0b013e318186fe37.

203. Handley AJ, Handley SA. Improving CPR performance using an audible feedback system suitable for incorporation into an automated external defibrillator. Resuscitation. 2003;57:57-62.

204. Skorning M, Beckers SK, Brokmann JCh, Rörtgen D, Bergrath S, Veiser T, Heussen N, Rossaint R. New visual feedback device improves performance of chest compressions by professionals in simulated cardiac arrest. Resuscitation. 2010;81:53-58. doi: 10.1016/j.resuscitation.2009.10.005.

205. Elding C, Baskett P, Hughes A. The study of the effectiveness of chest compressions using the CPR-plus. Resuscitation. 1998;36:169-173.

206. Sutton RM, Donoghue A, Myklebust H, Srikantan S, Byrne A, Priest M, Zoltani Z, Helfaer MA, Nadkarni V. The voice advisory manikin (VAM): an innovative approach to pediatric lay provider basic life support skill education. Resuscitation. 2007;75:161-168. doi: 10.1016/j. resuscitation.2007.02.007.

207. Isbye DL, Høiby P, Rasmussen MB, Sommer J, Lippert FK, Ringsted C, Rasmussen LS. Voice advisory manikin versus instructor facilitated training in cardiopulmonary resuscitation. Resuscitation. 2008;79:7381. doi: 10.1016/j.resuscitation.2008.06.012.

208. Oh JH, Lee SJ, Kim SE, Lee KJ, Choe JW, Kim CW. Effects of audio tone guidance on performance of CPR in simulated cardiac arrest with an advanced airway. Resuscitation. 2008;79:273-277. doi: 10.1016/j. resuscitation.2008.06.022.

209. Rawlins L, Woollard M, Williams J, Hallam P. Effect of listening to Nellie the Elephant during CPR training on performance of chest compressions by lay people: randomised crossover trial. BMJ. 2009;339:b4707.

210. Woollard M, Poposki J, McWhinnie B, Rawlins L, Munro G, O'Meara P. Achy breaky makey wakey heart? A randomised crossover trial of musical prompts. Emerg Med J. 2012;29:290-294. doi: 10.1136/ emermed-2011-200187.

211. Dold SK, Schmölzer GM, Kelm M, Davis PG, Schmalisch G, Roehr CC. Training neonatal cardiopulmonary resuscitation: can it be improved by playing a musical prompt? A pilot study. Am J Perinatol. 2014;31:245248. doi: 10.1055/s-0033-1345261.

212. Khanal P, Vankipuram A, Ashby A, Vankipuram M, Gupta A, DrummGurnee D, Josey K, Tinker L, Smith M. Collaborative virtual reality based advanced cardiac life support training simulator using virtual reality principles. J Biomed Inform. 2014;51:49-59. doi: 10.1016/j. jbi.2014.04.005.

213. Park CS, Kang IG, Heo SJ, Chae YS, Kim HJ, Park SS, Lee MJ, Jeong WJ. A randomised, cross over study using a mannequin model to evaluate the effects on CPR quality of real-time audio-visual feedback provided by a smartphone application. Hong Kong $J$ of Emerg Med. 2014;21:153-160.

214. Zapletal B, Greif R, Stumpf D, Nierscher FJ, Frantal S, Haugk M, Ruetzler K, Schlimp C, Fischer H. Comparing three CPR feedback devices and standard BLS in a single rescuer scenario: a randomised simulation study. Resuscitation. 2014;85:560-566. doi: 10.1016/j. resuscitation.2013.10.028.

215. Williamson LJ, Larsen PD, Tzeng YC, Galletly DC. Effect of automatic external defibrillator audio prompts on cardiopulmonary resuscitation performance. Emerg Med J. 2005;22:140-143. doi: 10.1136/ emj.2004.016444.

216. Mpotos N, Yde L, Calle P, Deschepper E, Valcke M, Peersman W, Herregods L, Monsieurs K. Retraining basic life support skills using video, voice feedback or both: a randomised controlled trial. Resuscitation. 2013;84:72-77. doi: 10.1016/j.resuscitation. 2012.08.320.

217. Roehr CC, Schmölzer GM, Thio M, Dawson JA, Dold SK, Schmalisch G, Davis PG. How ABBA may help improve neonatal resuscitation training: auditory prompts to enable coordination of manual inflations and chest compressions. J Paediatr Child Health. 2014;50:444-448. doi: 10.1111/jpc.12507.

218. Hillman K, Chen J, Cretikos M, Bellomo R, Brown D, Doig G, Finfer S, Flabouris A; MERIT study investigators. Introduction of the medical emergency team (MET) system: a cluster-randomised controlled trial. Lancet. 2005;365:2091-2097. doi: 10.1016/ S0140-6736(05)66733-5.

219. Priestley G, Watson W, Rashidian A, Mozley C, Russell D, Wilson J, Cope J, Hart D, Kay D, Cowley K, Pateraki J. Introducing Critical Care Outreach: a ward-randomised trial of phased introduction in a general hospital. Intensive Care Med. 2004;30:1398-1404. doi: 10.1007/ s00134-004-2268-7.

220. Baxter AD, Cardinal P, Hooper J, Patel R. Medical emergency teams at The Ottawa Hospital: the first two years. Can J Anaesth. 2008;55:223231. doi: 10.1007/BF03021506.

221. Campello G, Granja C, Carvalho F, Dias C, Azevedo LF, Costa-Pereira A. Immediate and long-term impact of medical emergency teams on cardiac arrest prevalence and mortality: a plea for periodic basic life-support training programs. Crit Care Med. 2009;37:3054-3061. doi: 10.1097/CCM.0b013e3181b02183.

222. Hayani O, Al-Beihany A, Zarychanski R, Chou A, Kharaba A, Baxter A, Patel R, Allan DS. Impact of critical care outreach on hematopoietic stem cell transplant recipients: a cohort study. Bone Marrow Transplant. 2011;46:1138-1144. doi: 10.1038/bmt.2010.248.

223. Jones S, Mullally M, Ingleby S, Buist M, Bailey M, Eddleston JM. Bedside electronic capture of clinical observations and automated clinical alerts to improve compliance with an Early Warning Score protocol. Crit Care Resusc. 2011;13:83-88.

224. Kenward G, Castle N, Hodgetts T, Shaikh L. Evaluation of a medical emergency team one year after implementation. Resuscitation. 2004;61:257-263. doi: 10.1016/j.resuscitation.2004.01.021.

225. Lim SY, Park SY, Park HK, Kim M, Park HY, Lee B, Lee JH, Jung EJ, Jeon K, Park CM, Ko MG, Park MR, Nam JM, Won SY, Jung JH, Cho SH, Suh GY. Early impact of medical emergency team implementation in a country with limited medical resources: a before-and-after study. J Crit Care. 2011;26:373-378. doi: 10.1016/j.jcrc.2010.08.019.

226. Patel MS, Jones MA, Jiggins M, Williams SC. Does the use of a "track and trigger" warning system reduce mortality in trauma patients? Injury. 2011;42:1455-1459. doi: 10.1016/j.injury.2011.05.030.

227. Rothberg MB, Belforti R, Fitzgerald J, Friderici J, Keyes M. Four years' experience with a hospitalist-led medical emergency team: an interrupted time series. J Hosp Med. 2012;7:98-103. doi: 10.1002/jhm.953.

228. Scherr K, Wilson DM, Wagner J, Haughian M. Evaluating a new rapid response team: NP-led versus intensivist-led comparisons. AACN Adv Crit Care. 2012;23:32-42. doi: 10.1097/NCI.0b013e318240e2f9.

229. Shah SK, Cardenas VJ Jr, Kuo YF, Sharma G. Rapid response team in an academic institution: does it make a difference? Chest. 2011;139: 1361-1367. doi: 10.1378/chest.10-0556.

230. Simmes FM, Schoonhoven L, Mintjes J, Fikkers BG, van der Hoeven JG. Incidence of cardiac arrests and unexpected deaths in surgical patients before and after implementation of a rapid response system. Ann Intensive Care. 2012;2:20. doi: 10.1186/2110-5820-2-20.

231. Snyder CW, Patel RD, Roberson EP, Hawn MT. Unplanned intubation after surgery: risk factors, prognosis, and medical emergency team effects. Am Surg. 2009;75:834-838. 
232. Subbe CP, Davies RG, Williams E, Rutherford P, Gemmell L. Effect of introducing the Modified Early Warning score on clinical outcomes, cardio-pulmonary arrests and intensive care utilisation in acute medical admissions. Anaesthesia. 2003;58:797-802.

233. Vazquez R, Gheorghe C, Grigoriyan A, Palvinskaya T, AmoatengAdjepong Y, Manthous CA. Enhanced end-of-life care associated with deploying a rapid response team: a pilot study. J Hosp Med. 2009;4: 449-452. doi: 10.1002/jhm.451.

234. Rothschild JM, Woolf S, Finn KM, Friedberg MW, Lemay C, Furbush KA, Williams DH, Bates DW. A controlled trial of a rapid response system in an academic medical center. Jt Comm J Qual Patient Saf. 2008;34:417-25, 365.

235. Al-Qahtani S, Al-Dorzi HM, Tamim HM, Hussain S, Fong L, Taher S, Al-Knawy BA, Arabi Y. Impact of an intensivist-led multidisciplinary extended rapid response team on hospital-wide cardiopulmonary arrests and mortality. Crit Care Med. 2013;41:506-517. doi: 10.1097/ CCM.0b013e318271440b.

236. Bellomo R, Goldsmith D, Uchino S, Buckmaster J, Hart GK, Opdam H, Silvester W, Doolan L, Gutteridge G. A prospective before-and-after trial of a medical emergency team. Med J Aust. 2003;179:283-287.

237. Buist MD, Moore GE, Bernard SA, Waxman BP, Anderson JN, Nguyen TV. Effects of a medical emergency team on reduction of incidence of and mortality from unexpected cardiac arrests in hospital: preliminary study. BMJ. 2002;324:387-390.

238. Laurens $\mathrm{N}$, Dwyer $\mathrm{T}$. The impact of medical emergency teams on ICU admission rates, cardiopulmonary arrests and mortality in a regional hospital. Resuscitation. 2011;82:707-712. doi: 10.1016/j. resuscitation.2010.11.031.

239. Moon A, Cosgrove JF, Lea D, Fairs A, Cressey DM. An eight year audit before and after the introduction of modified early warning score (MEWS) charts, of patients admitted to a tertiary referral intensive care unit after CPR. Resuscitation. 2011;82:150-154. doi: 10.1016/j. resuscitation.2010.09.480.

240. Sabahi M, Fanaei SA, Ziaee SA, Falsafi FS. Efficacy of a rapid response team on reducing the incidence and mortality of unexpected cardiac arrests. Trauma Mon. 2012;17:270-274. doi: 10.5812/traumamon.4170.

241. Dacey MJ, Mirza ER, Wilcox V, Doherty M, Mello J, Boyer A, Gates $\mathrm{J}$, Brothers T, Baute R. The effect of a rapid response team on major clinical outcome measures in a community hospital. Crit Care Med. 2007;35:2076-2082.

242. Sarani B, Palilonis E, Sonnad S, Bergey M, Sims C, Pascual JL, Schweickert W. Clinical emergencies and outcomes in patients admitted to a surgical versus medical service. Resuscitation. 2011;82:415-418. doi: 10.1016/j.resuscitation.2010.12.005.

243. Beitler JR, Link N, Bails DB, Hurdle K, Chong DH. Reduction in hospital-wide mortality after implementation of a rapid response team: a longterm cohort study. Crit Care. 2011;15:R269. doi: 10.1186/cc10547.

244. Konrad D, Jäderling G, Bell M, Granath F, Ekbom A, Martling CR. Reducing in-hospital cardiac arrests and hospital mortality by introducing a medical emergency team. Intensive Care Med. 2010;36:100-106. doi: 10.1007/s00134-009-1634-x.

245. Chan PS, Khalid A, Longmore LS, Berg RA, Kosiborod M, Spertus JA. Hospital-wide code rates and mortality before and after implementation of a rapid response team. JAMA. 2008;300:2506-2513. doi: 10.1001/ jama.2008.715.

246. Bristow PJ, Hillman KM, Chey T, Daffurn K, Jacques TC, Norman SL, Bishop GF, Simmons EG. Rates of in-hospital arrests, deaths and intensive care admissions: the effect of a medical emergency team. Med J Aust. 2000;173:236-240.

247. Lighthall GK, Parast LM, Rapoport L, Wagner TH. Introduction of a rapid response system at a United States veterans affairs hospital reduced cardiac arrests. Anesth Analg. 2010;111:679-686. doi: 10.1213/ ANE.0b013e3181e9c3f3.

248. Howell MD, Ngo L, Folcarelli P, Yang J, Mottley L, Marcantonio ER, Sands KE, Moorman D, Aronson MD. Sustained effectiveness of a primary-team-based rapid response system. Crit Care Med. 2012;40:25622568. doi: 10.1097/CCM.0b013e318259007b.

249. Santamaria J, Tobin A, Holmes J. Changing cardiac arrest and hospital mortality rates through a medical emergency team takes time and constant review. Crit Care Med. 2010;38:445-450. doi: 10.1097/ CCM.0b013e3181cb0ff1.

250. Chen J, Ou L, Hillman KM, Flabouris A, Bellomo R, Hollis SJ, Assareh H. Cardiopulmonary arrest and mortality trends, and their association with rapid response system expansion. Med J Aust. 2014;201:167-170.

251. Salvatierra G, Bindler RC, Corbett C, Roll J, Daratha KB. Rapid response team implementation and in-hospital mortality. Crit Care Med. 2014;42:2001-2006. doi: 10.1097/CCM.0000000000000347.

252. Chen J, Ou L, Hillman K, Flabouris A, Bellomo R, Hollis SJ, Assareh $\mathrm{H}$. The impact of implementing a rapid response system: a comparison of cardiopulmonary arrests and mortality among four teaching hospitals in Australia. Resuscitation. 2014;85:1275-1281. doi: 10.1016/j. resuscitation.2014.06.003.

253. Benson L, Mitchell C, Link M, Carlson G, Fisher J. Using an advanced practice nursing model for a rapid response team. Jt Comm J Qual Patient Saf. 2008;34:743-747.

254. Offner PJ, Heit J, Roberts R. Implementation of a rapid response team decreases cardiac arrest outside of the intensive care unit. J Trauma. 2007;62:1223-7; discussion 1227. doi: 10.1097/TA.0b013e31804d4968.

255. Moldenhauer K, Sabel A, Chu ES, Mehler PS. Clinical triggers: an alternative to a rapid response team. Jt Comm J Qual Patient Saf. 2009;35:164-174.

256. DeVita MA, Braithwaite RS, Mahidhara R, Stuart S, Foraida M, Simmons RL; Medical Emergency Response Improvement Team (MERIT). Use of medical emergency team responses to reduce hospital cardiopulmonary arrests. Qual Saf Health Care. 2004;13:251-254. doi: 10.1136/qhc.13.4.251.

257. Peberdy MA, Cretikos M, Abella BS, DeVita M, Goldhill D, Kloeck W, Kronick SL, Morrison LJ, Nadkarni VM, Nichol G, Nolan JP, Parr M, Tibballs J, van der Jagt EW, Young L. Recommended guidelines for monitoring, reporting, and conducting research on medical emergency team, outreach, and rapid response systems: an Utstein-style scientific statement: a scientific statement from the International Liaison Committee on Resuscitation (American Heart Association, Australian Resuscitation Council, European Resuscitation Council, Heart and Stroke Foundation of Canada, InterAmerican Heart Foundation, Resuscitation Council of Southern Africa, and the New Zealand Resuscitation Council); the American Heart Association Emergency Cardiovascular Care Committee; the Council on Cardiopulmonary, Perioperative, and Critical Care; and the Interdisciplinary Working Group on Quality of Care and Outcomes Research. Circulation. 2007;116:2481-2500. doi: 10.1161/ CIRCULATIONAHA.107.186227.

KEY WORDS: automated external defibrillator a cardiopulmonary resuscitation - medical emergency team a training 


\section{Circulation}

American

Heart

Association $_{\circledast}$

Part 8: Education, Implementation, and Teams: 2015 International Consensus on Cardiopulmonary Resuscitation and Emergency Cardiovascular Care Science With Treatment Recommendations

Farhan Bhanji, Judith C. Finn, Andrew Lockey, Koenraad Monsieurs, Robert Frengley, Taku

Iwami, Eddy Lang, Matthew Huei-Ming Ma, Mary E. Mancini, Mary Ann McNeil, Robert

Greif, John E. Billi, Vinay M. Nadkarni, Blair Bigham and on behalf of the Education, Implementation, and Teams Chapter Collaborators

Circulation. 2015;132:S242-S268

doi: 10.1161/CIR.0000000000000277

Circulation is published by the American Heart Association, 7272 Greenville Avenue, Dallas, TX 75231

Copyright (C) 2015 American Heart Association, Inc. All rights reserved.

Print ISSN: 0009-7322. Online ISSN: 1524-4539

The online version of this article, along with updated information and services, is located on the World Wide Web at:

http://circ.ahajournals.org/content/132/16_suppl_1/S242

\footnotetext{
Permissions: Requests for permissions to reproduce figures, tables, or portions of articles originally published in Circulation can be obtained via RightsLink, a service of the Copyright Clearance Center, not the Editorial Office. Once the online version of the published article for which permission is being requested is located, click Request Permissions in the middle column of the Web page under Services. Further information about this process is available in the Permissions and Rights Question and Answer document.
}

Reprints: Information about reprints can be found online at: http://www.lww.com/reprints

Subscriptions: Information about subscribing to Circulation is online at: http://circ.ahajournals.org//subscriptions/ 